\title{
Identifying Subseasonal Variability Relevant to Atlantic Tropical Cyclone Activity
}

\author{
Kurt A. Hansen, Sharanya J. Majumdar, And Ben P. Kirtman \\ Department of Atmospheric Sciences, Rosenstiel School of Marine and Atmospheric Science, Miami, Florida
}

(Manuscript received 31 December 2019, in final form 22 July 2020)

\begin{abstract}
The primary atmospheric oscillations and variables associated with subseasonal Atlantic tropical cyclone (TC) activity are identified, based on 37 years of reanalysis data. TC activity, represented by accumulated cyclone energy (ACE), is computed for combined phases of the Madden-Julian oscillation (MJO) and El Niño-Southern Oscillation (ENSO). The MJO influence on TC activity becomes greater when the ENSO state is cooler. There is also a shift in the favorable MJO phase for TC activity with ENSO state. For strong La Niñas, MJO phases 4 and 5 (enhanced convection over the Maritime Continent) are most likely to have above-average ACE. To investigate other potential factors that influence subseasonal TC activity, two novel methods are developed: ACE by year (ABY) and seasonal and climatology removed (SNCR). Both methods isolate subseasonal signals of environmental conditions in association with a variable of interest. Vorticity, sea surface temperature, relative humidity, and genesis potential all show little signal in association with subseasonal Atlantic TC activity. The most important identifier of enhanced TC activity is negative vertical wind shear anomalies in the main development region of the Atlantic basin, and positive shear anomalies in the subtropical Atlantic. The shear pattern associated with a favorable MJO for TCs is similar to but distinct from the shear pattern associated with enhanced subseasonal TC activity. These findings demonstrate a nonlinear MJO-ENSO interaction and a pattern of wind shear anomalies that is linked to subseasonal TC activity.
\end{abstract}

\section{Introduction}

Subseasonal time scales straddle the line between weather and climate and focus on time frames between approximately two and six weeks. Subseasonal forecasts have many potential uses in public health, disaster preparedness, water management, energy, and agriculture (White et al. 2017). However, bridging the gap between weather and climate predictions has been difficult. Information inherited from the initial conditions of mesoscale systems drops to near zero by two weeks (Dalcher and Kalnay 1987; Komaromi and Majumdar 2014; Zhang et al. 2019), and influence from boundary conditions is not felt sufficiently strongly on these relatively short time scales (Robertson et al. 2020). This has led some scientists to call the subseasonal range the "predictability desert" (Vitart et al. 2012).

Tropical cyclones (TCs) are of particular interest in subseasonal forecasting because they are high-impact

Corresponding author: Kurt A. Hansen, kurt.hansen@rsmas. miami.edu weather events with large variability on subseasonal time scales (Gray 1979). For example, in August 2018, climatologically one of the most active months for Atlantic TC activity, no named storms formed in the tropical Atlantic (south of $30^{\circ} \mathrm{N}$ ). However, the following week, four TCs developed in the Atlantic, including Hurricane Florence, which caused widespread destruction in the Carolinas. Overall, there is a solid understanding of the atmospheric and oceanic factors that govern TC activity on weather and seasonal time scales, and modes of climate variability that influence TC activity on subseasonal time scales. This provides some grounds for optimism that there may be predictability of TC activity in the subseasonal time frame. Several methods have been used to show that TC prediction at subseasonal time scales can be skillful, including a combination of aspects of both weather and climate predictions for TC activity (Vitart et al. 2010).

One of the main sources of seasonal variability is El Niño-Southern Oscillation (ENSO). ENSO represents a change in the sea surface temperatures (SST) and pressure gradients in the equatorial Pacific Ocean that 
impacts the global atmospheric circulation pattern (Rasmusson and Wallace 1983). During the warm phase of ENSO, or El Niño, Atlantic TC activity is typically below average. Although the interaction between ENSO and TC activity is multifaceted, studies have consistently shown that during El Niño events, vertical wind shear increases in the tropical Atlantic, which inhibits Atlantic TC activity (Gray 1984; Goldenberg and Shapiro 1996; Tang and Neelin 2004). El Niño may also create unfavorable conditions for TC activity in the Atlantic through increased stability and decreased midlevel relative humidity (RH) (Tang and Neelin 2004; Klotzbach and Oliver 2015a; Camargo et al. 2007).

On subseasonal time scales, the primary source of predictability comes from the Madden-Julian oscillation (MJO) (Janiga et al. 2018). The MJO is a slow propagating global wave pattern centered on the equator with a period of 40-90 days (Jones et al. 2004; Kim et al. 2018). Skillful prediction of the MJO can occur for lead times of up to five weeks (Kim et al. 2018). During the westerly phase of the MJO in the Atlantic [or phases 1,2 , and 3 of the widely used real-time multivariate MJO (RMM) index of Wheeler and Hendon (2004)], enhanced TC genesis was found to occur in the tropical Atlantic. From 1949 to 1997, the westerly phase of the MJO was associated with 50 cases of genesis west of $77.5^{\circ} \mathrm{W}$ compared with 14 cases for the easterly phase (Maloney and Hartmann 2000). Other measures of TC activity also vary with MJO phase; accumulated cyclone energy (ACE; Bell et al. 2000) in the Atlantic basin was found to increase by $25 \%$ during MJO phases 2 and 3 (Vitart 2009). Furthermore, the number of major hurricane days in MJO phases 1 and 2 was found to be three times higher than in phases 6 and 7 (Klotzbach 2010). However, in spite of these statistical results, the physical connections between the MJO and Atlantic TC activity are somewhat unclear. The MJO is hypothesized to modify environmental conditions in the Atlantic by decreasing vertical wind shear and increasing relative vorticity and RH (Klotzbach 2010; Camargo et al. 2009; Maloney and Hartmann 2000). The MJO may also influence genesis through an increased number of disturbances (Liebmann et al. 1994) or through amplification of African easterly waves (AEWs), the precursor to many Atlantic TCs (Aiyyer and Molinari 2008).

Although the separate influences of ENSO or the MJO on TC activity have been investigated in detail (Camargo et al. 2007, 2009), their combined influence on TC activity has only recently received attention. Klotzbach and Oliver (2015b) showed that there is more variability of TC activity with MJO phase during $\mathrm{La}$ Niñas. Additionally, linear models incorporating measures of the MJO and ENSO (Leroy and Wheeler 2008;
Vitart et al. 2010; Klotzbach 2007) have shown skill in predicting TC activity in the subseasonal range. However, since these linear models do not capture nonlinear interactions between phenomena such as ENSO and the MJO, they do not provide the physical connections guiding subseasonal variability. Hence, the full spectrum of ENSO-MJO interaction on TC activity remains to be explored. While other subseasonal oscillations like Kelvin waves have been shown to impact TC activity (Schreck 2016), there is a fundamental gap in the understanding of how variability of environmental fields, such as shear and humidity, impact subseasonal TC activity in the Atlantic.

Several studies have used general circulation models (GCMs) to obtain detailed predictions of subseasonal TC activity (Lee et al. 2018; Camp et al. 2018; Belanger et al. 2010; Vitart et al. 2010; Elsberry et al. 2010). However, GCMs do not accurately represent TC climatology, intensity distribution or TC structure. This inability of GCMs to resolve TCs likely inhibits their ability to predict them (Lee et al. 2018). Many studies have corrected for model biases such as Vitart et al. (2010) and Camp et al. (2018). While these corrections do improve the skill, they reduce the meaningful physical interpretations of the model output.

In this paper, we seek to identify indicators of TC activity on subseasonal time scales, with a future goal to provide GCMs with new predictive tools that are not dependent on accurate TC representation. First, we establish how the nonlinear interaction of the MJO and ENSO work to influence Atlantic TC activity. Second, we aim to identify environmental indicators of subseasonal TC activity other than the MJO. Environmental parameters may provide broader methods of verification that are not limited by discrete quantities of TC existence (such as TC count). We emphasize that while seasonal variability can contribute to subseasonal skill, this study focuses on environmental indications of TC activity on subseasonal time scales.

In section 2 we describe the data and methods used in this paper. Section 3 discusses TC activity in relation to the independent variables of MJO and ENSO phase. Section 4 explores the signals in environmental fields such as shear and RH in relation to subseasonal TC activity. A summary of results is given in section 5, and future work is reviewed in section 6 .

\section{Data and methods}

\section{a. Atmospheric variables}

The primary variables used in this study are horizontal wind, humidity, air temperature and SST, retrieved from the European Centre for Medium-Range Weather 
Forecasts (ECMWF) interim reanalysis dataset (ERAI; Dee et al. 2011). The ERAI dataset used here has a horizontal grid spacing of $1^{\circ} \times 1^{\circ}$ and 60 vertical levels. Daily data from the three peak months of the Atlantic hurricane season, August, September and October, which account for about $88 \%$ of Atlantic ACE, are utilized over a 37-yr period (1979-2015).

\section{b. El Niño-Southern Oscillation}

Daily SST anomalies from ERAI averaged over the Niño-3.4 region $\left(5^{\circ} \mathrm{N}-5^{\circ} \mathrm{S}, 170^{\circ}-120^{\circ} \mathrm{W}\right)$ are used to define the strength of ENSO. ${ }^{1}$ To investigate subseasonal activity during distinct anomalous phases of ENSO, the dataset was divided into ranked terciles (warm, neutral, and cool) with thresholds of $0.32^{\circ}$ and $-0.39^{\circ} \mathrm{C}$, a slightly lower magnitude than the standard oceanic Niño index (ONI) threshold of $0.5^{\circ} \mathrm{C}$. Discrepancies between thresholds may occur due to the ONI being calculated with 3-month running means over the whole seasonal cycle, as opposed to daily data during August-October. The warm and cool terciles will be referred to as El Niño and La Niña, respectively.

\section{c. Madden-Julian oscillation}

The seasonally independent RMM index (Wheeler and Hendon 2004) is used to define the MJO phase and amplitude, using 850- and 200-hPa zonal wind fields from the National Centers for Environmental Prediction (NCEP) reanalysis dataset (Kalnay et al. 1996), and satellite-based outgoing longwave radiation (OLR) data over the 37-yr period from 1979 to 2015. To isolate subseasonal variability, ENSO is filtered out of the analysis fields by subtracting the 120-day running means prior to calculating the EOFs, using a similar technique to Wheeler and Hendon (2004). More information on this technique and data can be found in Arcodia et al. (2020). The projection of daily observed data onto the first two empirical orthogonal functions (EOFs) yields the RMM1 and RMM2 principal component time series, with an amplitude and eight phases. An amplitude that does not exceed 1 is considered to be a weak MJO. Each phase roughly indicates the region in the tropics in which convection is most active, although impacts from the MJO extend globally.

\section{d. Tropical cyclone activity}

The 6-hourly TC data from the National Hurricane Center "best track" hurricane database (HURDAT2; Landsea and Franklin 2013) are retrieved from the

\footnotetext{
${ }^{1}$ Monthly data from NOAA ERSSTv5 were also compared to ERAI data and the dataset did not meaningfully change the results.
}

International Best Track Archive for Climate Stewardship (IBTrACS; Knapp et al. 2010). TC activity is quantified using ACE, defined as the summation of the square of the maximum sustained surface winds [in knots $(\mathrm{kt} ; 1 \mathrm{kt} \approx$ $\left.0.51 \mathrm{~m} \mathrm{~s}^{-1}\right)$ ] for a TC at each 6-h interval. For this study, ACE is calculated for TCs with maximum sustained winds exceeding $34 \mathrm{kt}$ in the North Atlantic south of $30^{\circ} \mathrm{N}$. We select ACE because of its utility as a continuous function and for the added weight toward more intense TCs, although, we also considered other metrics such as genesis and TC days.

\section{e. Proxy environmental indicators of TC activity: Genesis indices}

Several environmental factors are known to influence TC genesis and activity. Low-level absolute vorticity $\eta$ is needed for a TC to organize (Gray 1979). High values of vertical wind shear $V_{\text {shear }}$, defined here as the magnitude of the difference between the 200- and 850-hPa wind vectors, usually inhibits strengthening in TCs. Increased values of both atmospheric instability and lower-middle tropospheric RH are more conducive for vertical development of the TC, which allows for strengthening. Warm SSTs provide fluxes of heat and moisture that are necessary for TC formation and intensification (Gray 1979). In addition to investigating these environmental fields individually, these fields can be combined to produce bulk measures. For example, the potential intensity (PI) is a theoretical maximum of the sustained winds that a TC can attain, given a prescribed SST and an estimate of the atmospheric instability represented by the vertical profile of temperature and humidity (Bister and Emanuel 2002).

Since one of our main objectives is to examine the combined influence of environmental parameters on subseasonal TC activity, a metric that uses these parameters to quantify the potential for TC activity is required. This metric needs to be easily computable from gridded reanalysis data (in this study) and subseasonal ensemble forecast data (in future forecast evaluation studies). The first metric to be tested in this study is the genesis potential index (GP) from Emanuel and Nolan (2004). GP was created subjectively based on the parameters from Gray (1979) and was shown to correlate well with TC genesis on climatological time scales. GP is defined as

$$
\mathrm{GP}=\left|10^{5} \eta\right|^{3 / 2}\left(\frac{\mathrm{RH}}{50}\right)^{3}\left(\frac{\mathrm{PI}}{70}\right)^{3}\left(1+0.1 V_{\text {Shear }}\right)^{-2},
$$

where $\eta$ is $850-\mathrm{hPa}$ vorticity, $\mathrm{RH}$ is $700-\mathrm{hPa} \mathrm{RH}(\%)$, PI is potential intensity $\left(\mathrm{m} \mathrm{s}^{-1}\right)$, and $V_{\text {Shear }}$ is the $200-850-\mathrm{hPa}$ vertical wind shear magnitude $\left(\mathrm{m} \mathrm{s}^{-1}\right)$. 
To capture subseasonal environmental variability, the fluctuations on smaller spatial scales (mesoscale) and shorter time scales ("weather," on the order of 1 day) need to be filtered out. For GP, this is done by computing a normalized daily GP anomaly $\left(\mathrm{GP}_{N}^{\prime}\right)$ by taking the $N$-day running mean of the raw GP and subtracting the climatological running mean value of GP (from the 1979-2015 data) for the associated day $\left(\mathrm{GP}_{N \text {,climo }}\right)$ and then normalizing it by the daily standard deviation of the $N$-day running mean value of $\mathrm{GP},\left(\mathrm{GP}_{N, \text { sdev }}\right)$ :

$$
\begin{aligned}
& \mathrm{GP} \equiv \mathrm{GP}\left(\text { day, year, lat, lon; } \eta, \mathrm{RH}, \mathrm{PI}, V_{\text {shear }}\right) \\
& \begin{aligned}
\mathrm{GP}_{N}^{\prime}(\text { day, year, lat, lon }) \\
=\frac{\mathrm{GP}_{N}(\text { day, year, lat, lon })-\mathrm{GP}_{N, \text { climo }}(\text { day, lat, lon })}{\mathrm{GP}_{N, \text { sdev }}(\text { day, lat, lon })} .
\end{aligned}
\end{aligned}
$$

GP was compared against the Tippett-Camargo-Sobel (TCS) index (Tippett et al. 2011) to qualify the use of these indices on subseasonal time scales. There is good agreement between these two indices in terms of the environment produced by the MJO on subbasin scales, lending credence to the use of GP for subseasonal analysis. A detailed account of this analysis is provided in appendix A.

Several caveats should be considered when using the GP and TCS indices. Both of these metrics were created based on TC genesis for use in climate studies, which has been shown to introduce errors on subseasonal time scales (Menkes et al. 2012). However, GP has been used on subseasonal time scales to diagnose the impacts of the MJO on conditions in the Atlantic (Camargo et al. 2009). The relative agreement between TCS and GP gives some confidence that these indices capture physical signals on subbasin scales, although it is worth acknowledging the possibility that both indices are subject to the same biases. Some inconsistency is also possible because these indices are being evaluated for TC activity using ACE, rather than the originally intended purpose of genesis. However, since many of the environmental parameters favoring genesis are nearly the same as those that favor strengthening and persistence of TCs, we expect this discrepancy to be minor.

Both the TCS index and monthly running averages of the GP index mix signals from multiple phases of the MJO. On the other hand, running averages on the order of 1 day mainly capture variability associated with individual "weather" disturbances. We therefore elect to use a 5-day running mean $\left(\mathrm{GP}_{5}^{\prime}\right)$ to represent the subseasonal variability of the environment, since 5 days approximately represents the average duration of the MJO passing through one phase.

\section{f. Removing ENSO and seasonal signals}

To isolate the subseasonal variability of environmental variables relevant to Atlantic TC activity, seasonal modes of variability, especially ENSO, need to be removed. To accomplish this, we introduce two new methods: (i) ACE by year (ABY), and (ii) seasonal mean and climatology removed (SNCR). Both of these methods are selective composites that find the spatial subseasonal signal of an environmental variable "VAR" (such as GP) in association with the subseasonal variability of a single "anchoring" parameter (such as ACE) that varies only in time. In other words, these methods will be used to select periods that are representative of subseasonal variability based on the anchor. Composite analyses of physical parameters (i.e., VAR) will be averaged across all of these selected periods.

Both the ABY and SNCR methods are designed to ensure that the variability and total value of the "anchoring" parameter are independent of the seasonal cycle. To accomplish this, ACE is first calculated for all TCs in the Atlantic Basin south of $30^{\circ} \mathrm{N}$ to exclude TCs that form from extratropical cyclones, which develop from different processes and in different environments than other TCs (McTaggart-Cowan et al. 2013). The 5-day running sums of $\mathrm{ACE}\left(\mathrm{ACE}_{5}\right)$ are computed from the daily values. The climatological values of these 5-day running sums $\left(\mathrm{ACE}_{5, \text { climo }}\right)$ are then computed, representing the average seasonal cycle (e.g., higher values in mid-September, lower values in late October). ACE anomalies are then calculated about this climatology. The magnitude of ACE anomalies also has a seasonal component. To eliminate this, they are normalized by the standard deviation of the 5-day sum ACE $\left(\mathrm{ACE}_{5, \text { sdev }}\right)$. This results in a normalized anomaly $\left(\mathrm{ACE}_{5}^{\prime}\right)$ that isolates periods of unusually high or low TC activity:

$\mathrm{ACE}_{5}^{\prime}($ day, year $)=\frac{\mathrm{ACE}_{5}(\text { day, year })-\mathrm{ACE}_{5, \mathrm{climo}}(\text { day })}{\mathrm{ACE}_{5, \text { sdev }}(\text { day })}$.

While ACE is used in this study, ABY and SNCR can be generalized to be anchored on any time-varying quantity in place of ACE in the above equation (e.g., areaaveraged precipitation; see appendix $\mathrm{B}$ ).

The next step is to design the ABY and SNCR methods to remove interseasonal variability. Both of these methods are means of selecting days that equally represent active and inactive years, so that signals from ENSO and other seasonal or longer-period oscillations such as the Atlantic meridional mode (AMM) and the 
Atlantic multidecadal oscillation (AMO), are removed while subseasonal variability is retained (Kossin and Vimont 2007; Goldenberg et al. 2001; Servain et al. 1999).

The ABY technique is a composite of conditions associated with the top $\mathrm{ACE}_{5}^{\prime}$ events for each year. To calculate $\mathrm{ABY}$, the 30 days corresponding to the top $33 \%$ of $\mathrm{ACE}_{5}^{\prime}$ values during each August-October period (denoted " $i \mathrm{ABY}$ ") are indexed. For the selected environmental variable, "VAR," the daily anomalies of VAR are averaged across these indexed days ( $i \mathrm{ABY})$ over all years. The ABY technique produces a field associated with above average subseasonal TC activity based on an equal number of days from each year regardless of total seasonal TC activity. This acts to remove the influence of seasonal and interannual oscillations. An example equation of the ABY technique is as follows:

$$
\begin{aligned}
& \overline{\operatorname{VAR}_{5}^{\prime \mathrm{ABY}}} \text { (lat, lon) } \\
& =\frac{1}{N_{i \mathrm{ABY}}} \sum_{i \mathrm{ABY}} \mathrm{VAR}_{5}^{\prime} \text { (lat, lon, day, year). }
\end{aligned}
$$

The SNCR method is roughly based off of the ENSO removal method used in Lin et al. (2008) and the process used in Maloney and Shaman (2008), although our analysis for TC activity is constrained by our 92-day window of the active portion of the Atlantic TC season. The SNCR method first takes the average values of $\mathrm{ACE}_{5}^{\prime}$ over August-October in each year, resulting in 37 annual values. This average is then subtracted from the daily values of $\mathrm{ACE}_{5}^{\prime}$ for that particular year, essentially creating a daily anomaly with respect to the total activity across that season:

$$
\overline{\mathrm{ACE}_{5}^{\prime S N C R}}(\text { day, year })=-\frac{1}{92} \sum_{\text {day }=1}^{92} \mathrm{ACE}_{5}^{\prime}(\text { day, year }) .
$$

Over each August-October period, $\mathrm{ACE}_{5}^{\mathrm{SNCR}}$ has an average value of zero, but the subseasonal variability is retained. To compute the VAR anomalies associated with SNCR, the 1135 days corresponding to the top $33 \%$ of daily $\mathrm{ACE}_{5}^{\text {SNCR }}$ values during August-October over the entire sample for 1979-2015 (denoted "iSNCR") are indexed. The corresponding VAR anomalies are then averaged over these 1135 days. An example of the SNCR technique is as follows:

$$
\begin{aligned}
& \overline{\operatorname{VAR}_{5}^{\text {SNCR }}} \text { (lat, lon) } \\
& =\frac{1}{N_{i \mathrm{SNCR}}} \sum_{i \mathrm{SNCR}} \mathrm{VAR}_{5}^{\prime}(\text { lat, lon, day, year). }
\end{aligned}
$$

The field created using SNCR is a composite of VAR anomalies associated with anomalies of $\mathrm{ACE}_{5}^{\prime}$ relative to both the annual cycle and the season average. SNCR does not sample each year equally but rather looks at the most anomalous periods of TC activity in comparison to the total activity in the surrounding season. Both SNCR and ABY remove seasonal signals but retain subseasonal variability, which is demonstrated in appendix B.

\section{g. TC removal}

Since TCs can influence their own environment, notably through increased RH, vorticity, and uppertropospheric divergence (Gray 1979), our analysis of the background environment may be substantially influenced by TCs themselves. To prevent contamination from TCs, all daily data within $5^{\circ}$ of TC centers are masked. For some fields, such as vorticity, removing TCs has a large impact on the resulting field.

\section{ACE anomalies and genesis potential associated with ENSO and the MJO}

In this section, the combined influence of ENSO and the MJO on TC activity is quantified, in order to provide a simple climatology that can be used to improve subseasonal predictions, and to identify potential new gaps in our physical understanding of the nonlinear response of TC activity to the MJO and ENSO.

\section{a. Individual influence of ENSO and the MJO on $A C E$}

We first provide a calculation of TC activity observed in individual ENSO and MJO phases by computing daily values of normalized ACE anomalies in each phase. Consistent with previous studies (Gray 1984; Goldenberg and Shapiro 1996), El Niño events are associated with lower TC activity, and La Niñas are associated with higher TC activity (Fig. 1). ENSO neutral years (middle tercile) are near or slightly less active than normal with average normalized daily ACE anomalies of $-0.07 .^{2}$ The MJO phases produce daily normalized ACE anomalies of comparable magnitudes to the anomalies associated with ENSO (Fig. 2). The strongest normalized ACE anomalies occur in MJO phases 2,7 , and 8 , with phase 2 being the only one having a large positive anomaly of $0.61 .^{3}$ Phases 1,3 , and 4 are also associated with above-normal ACE. For the

\footnotetext{
${ }^{2} n=1135$; $95 \%$ confidence interval: from -0.17 to 0.03 normalized ACE; $p=0.19$. Statistics use a two-tailed $t$ test to obtain the $p$ value.

${ }^{3} n=212$; 95\% confidence interval: $0.23-0.99$ normalized ACE; $p=0.002$.
} 


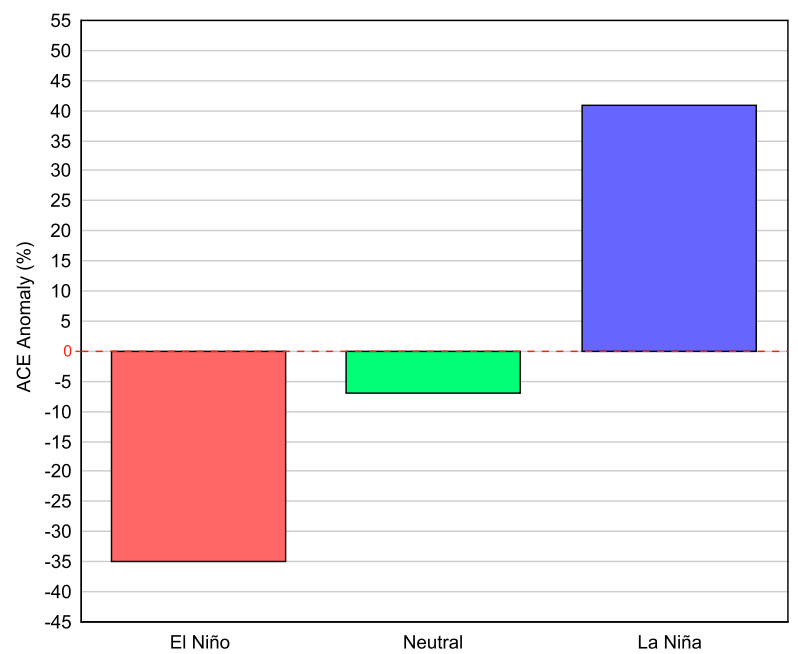

FIG. 1. Fraction of daily values of ACE associated with ENSO phases, expressed as a percentage of average normalized ACE.

rest of this study we use MJO combined phases 1 and 2 to indicate the "favorable" phases of the MJO for TC activity as they have the highest positive normalized ACE anomalies. While phases 7 and 8 are associated with the lowest values of ACE, phases 5 and 6 also have negative anomalies and are used as the exemplary phases for "unfavorable" conditions primarily because they are shifted approximately $180^{\circ}$ from phases 1 and 2 . It is worth emphasizing these ENSO and MJO statistics are averages, and individual cases can vary greatly from these mean values.

\section{b. Combined influence of ENSO and MJO on ACE}

The next step is to investigate the combined effects of MJO and ENSO as they are not expected to act independently. The ENSO phase is known to influence aspects of the MJO; for instance, convection associated with the MJO persists farther east into the east Pacific during El Niño (Zhang 2005). In Fig. 3, the ENSO SST anomalies and eight $\mathrm{MJO}$ phases are divided into bins, and the values of $\mathrm{ACE}_{5}^{\prime}$ averaged within each bin are produced in this ENSO-MJO phase space. There are several interesting findings. First, as expected, generally positive values of $\mathrm{ACE}_{5}^{\prime}$ are evident during strong MJO phases 1 and 2 (Fig. 3b) while La Niñas are present. However, this is less clear during El Niños. As the ENSO SST anomaly increases, the difference in $\mathrm{ACE}_{5}^{\prime}$ between the most active and least active MJO phase becomes smaller. Stronger MJOs are more consistent than weak MJOs in producing positive $\mathrm{ACE}_{5}^{\prime}$ anomalies in phases 1 and 2 and negative $\mathrm{ACE}_{5}^{\prime}$ anomalies in phases 7 and 8. Generally, $\mathrm{ACE}_{5}^{\prime}$ is higher when ENSO anomalies are cooler, although individual cases can vary greatly from these means.

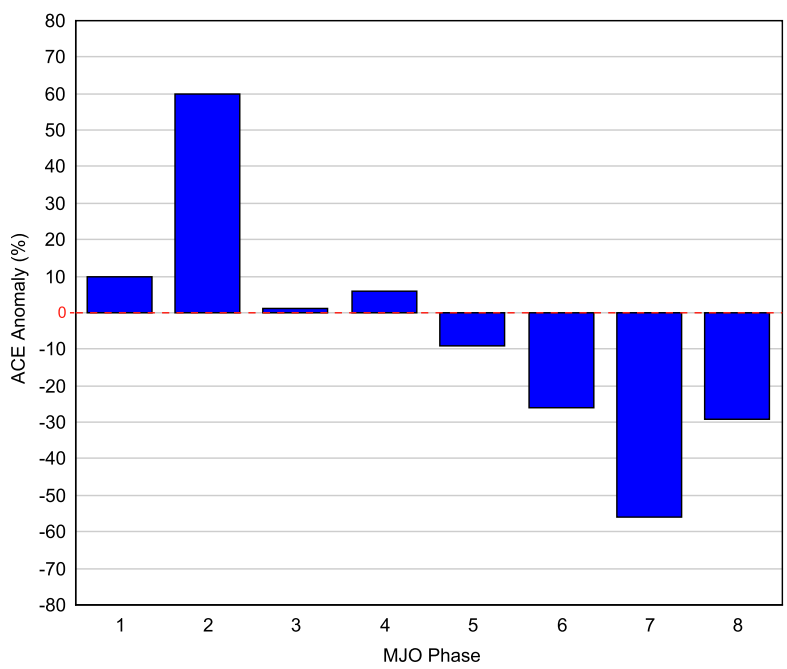

FIG. 2. Fraction of daily values of ACE associated with strong phases of the MJO (with RMM amplitude > 1), expressed as a percentage of average normalized ACE.

An alternative way to examine the relationship between TC activity and the combined ENSO and MJO phases is via probability density function (PDF) anomalies of active $\mathrm{ACE}_{5}^{\prime}$ periods (Fig. 4). PDFs allow for separate analysis of generally active periods (i.e., top $33 \%$ ) and extremely active (i.e., top $10 \%$ ) of $\mathrm{ACE}_{5}^{\prime}$ events and validates that the binned average $\mathrm{ACE}_{5}^{\prime}$ values in Fig. 3 are not dominated by outliers. Two groups for each phase of the $\mathrm{MJO}$, and 16 phases of ENSO SST between $-2^{\circ}$ and $2^{\circ} \mathrm{C}$ (i.e., in $0.25^{\circ}$ increments), are used to make 256 bins. The relative frequency of active $\mathrm{ACE}_{5}^{\prime}$ events and all events is calculated for each bin to produce the PDFs. The total PDF is then subtracted from the PDF of the top ACE events. Because of the large number of bins, the percent values of the PDFs and anomalies are small. The maximum value in the PDF of all MJO-ENSO combined events is about $2 \%$, and the PDF of ACE anomalies is about $1 \%$. While it was shown in Fig. 3 that the strong positive and negative ENSO phases dominated the pattern of $\mathrm{ACE}_{5}^{\prime}$, these phases only occur rarely. The PDFs (Fig. 4) demonstrate that most of the time the MJO plays a large role, if not the more important role relative to ENSO, in determining weekly TC activity.

The PDFs display a similar pattern regardless of MJO strength or threshold for TC activity (represented by the top $10 \%$ or top $33 \%$ of $\mathrm{ACE}_{5}^{\prime}$ ). MJO phases $1-3$ and cooler ENSO events exhibit higher probabilities of increased TC activity. This pattern is consistent with previous research and our findings in Fig. 3. However, there are some deviations from this general pattern. Highly active periods of TC activity (top $10 \%$ of all $\mathrm{ACE}_{5}^{\prime}$ values) are more dependent on the MJO phase. 


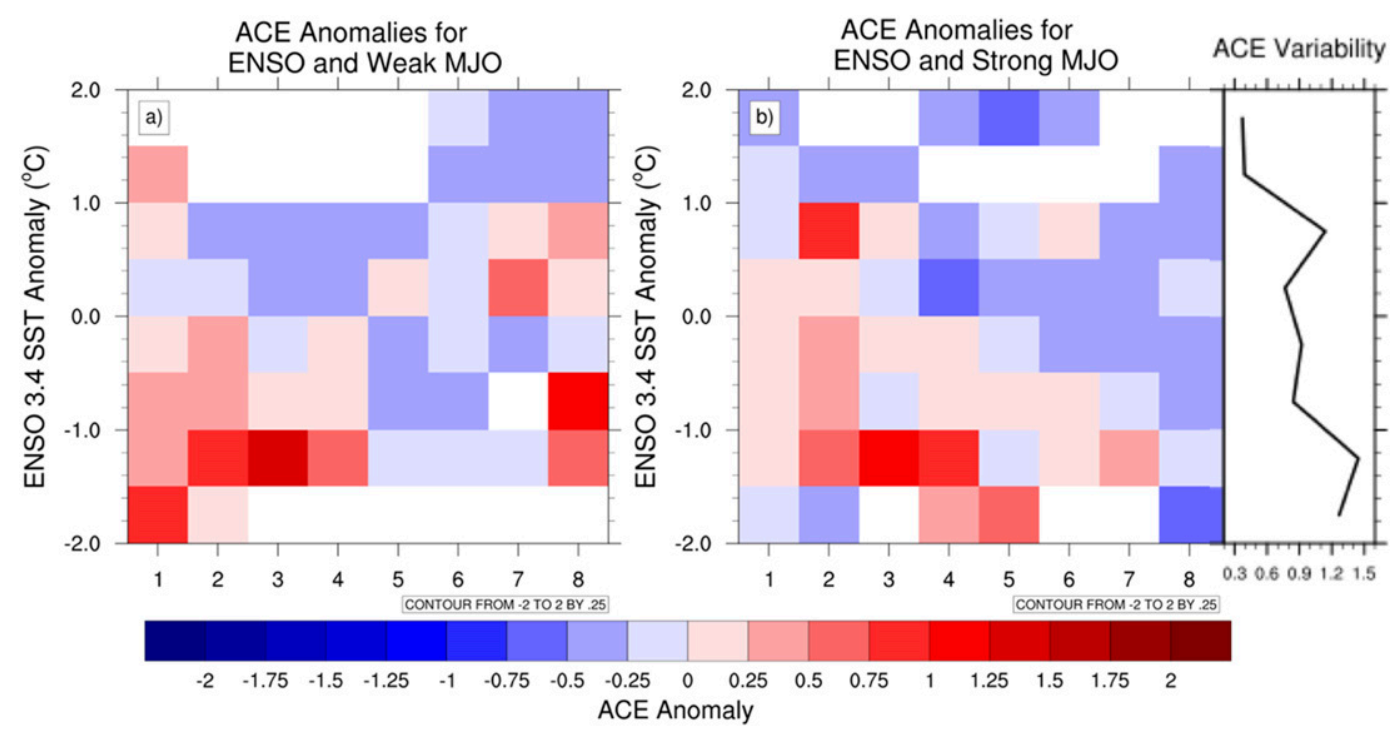

FIG. 3. (a) Average $\mathrm{ACE}_{5}^{\prime}$ for joint bins of $0.5^{\circ} \mathrm{C}$ Niño-3.4 SST with weak MJO phases (amplitude $<1$ ). (b) Average $\mathrm{ACE}_{5}^{\prime}$ for joint bins of $0.5^{\circ} \mathrm{C}$ Niño-3.4 SST with strong MJO phases (amplitude $>1$ ). The line graph in (b) shows the range of $\mathrm{ACE}_{5}^{\prime}$ among $\mathrm{MJO}$ phases as a function of Niño-3.4 SST anomalies. Bins with less than seven samples are left blank.

This discrepancy is more apparent for strong MJO cases. When the MJO is strong, very high TC activity is also more likely in $\mathrm{MJO}$ phases 1 and 2 during weak warm events (SST anomalies between $0^{\circ}$ and $1^{\circ} \mathrm{C}$ ). In contrast, when the MJO is weak, very high TC activity is unlikely in MJO phases 1 and 2 for nearly all warm ENSO SST anomalies. This finding suggests that the MJO modulates periods of TC activity when background conditions are sufficiently favorable. There is also a shift in the TC favorable phase of the MJO with ENSO phase. For strong MJOs, there is an increased likelihood of the top $10 \%$ of TC activity in strong La Niñas for MJO phases 4 , 5 and 6 (Fig. 4d). This could be attributed to a strong La Niña overpowering the MJO signal. However, in the usually favorable MJO phases there is a neutral if not slightly negative PDF anomaly for strong La Niñas, in agreement with $\mathrm{ACE}_{5}^{\prime}$ anomalies in Fig. 3. This pattern also does not appear during weak MJO phases. This contradicts the expected results of the ENSO and MJO phases considered individually.

Both ACE anomalies (Fig. 3b) and PDF anomalies (Figs. 4c,d) show a negative slope in the most active MJO phase as a function of Niño-3.4 SSTs. This implies that the state of ENSO affects which phase of the MJO is most favorable. Most years with ENSO neutral conditions can expect more TC activity in phases 1 and 2, but during strong La Niñas the typically unfavorable MJO phases 5 and 6 may be associated with more activity. One explanation for this shift may be that strong La Niñas may produce nonclimatalogical easterly shear
(Klotzbach 2011), and MJO phases 5 and 6, which normally add to the climatalogical westerly shear, may counteract this.

\section{c. Individual influence of ENSO and MJO on GP}

To evaluate the physical mechanisms governing ENSO and MJO interaction with TC activity, we first use GP to evaluate the environmental conditions. An analysis of the influences of individual ENSO and MJO phases on environmental conditions using GP has previously been conducted by Camargo et al. (2007, 2009). Although we use a different reanalysis dataset, preprocessing procedure and a slightly different GP equation, our $\mathrm{GP}_{5}^{\prime}$ anomalies associated with the MJO and ENSO, illustrated in Fig. 5, generally agree with results found by Camargo et al. (2009). Interestingly, the $\mathrm{GP}_{5}^{\prime}$ signal associated with strong cases of the MJO (Figs. 5b,d) is generally higher than the $\mathrm{GP}_{5}^{\prime}$ magnitude associated with ENSO (Figs. 5a,c). Additionally, $\mathrm{GP}_{5}^{\prime}$ values associated with the MJO extend farther east into the main development region (MDR, $10^{\circ}-20^{\circ} \mathrm{N}, 80^{\circ}-20^{\circ} \mathrm{W}$ ), a region that is particularly important for Atlantic TC activity (Goldenberg et al. 2001). These indicate that $\mathrm{GP}_{5}^{\prime}$ signals from the MJO may be stronger than their counterparts from ENSO. It is worth noting that the smaller number of cases of strong MJO phases 1 and 2 may accentuate the anomalies.

To build on the insights from Camargo et al. (2007, 2009), we now investigate GP anomalies for combined phases of ENSO and MJO. As expected, $\mathrm{GP}_{5}^{\prime}$ anomalies 
Top 33\% ACE PDF Anomaly (Weak MJO)

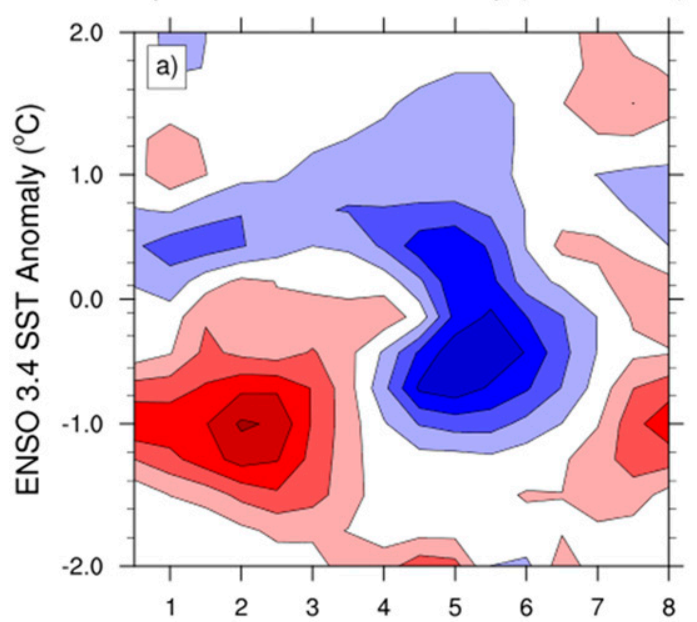

Top 33\% ACE PDF Anomaly (Strong MJO)

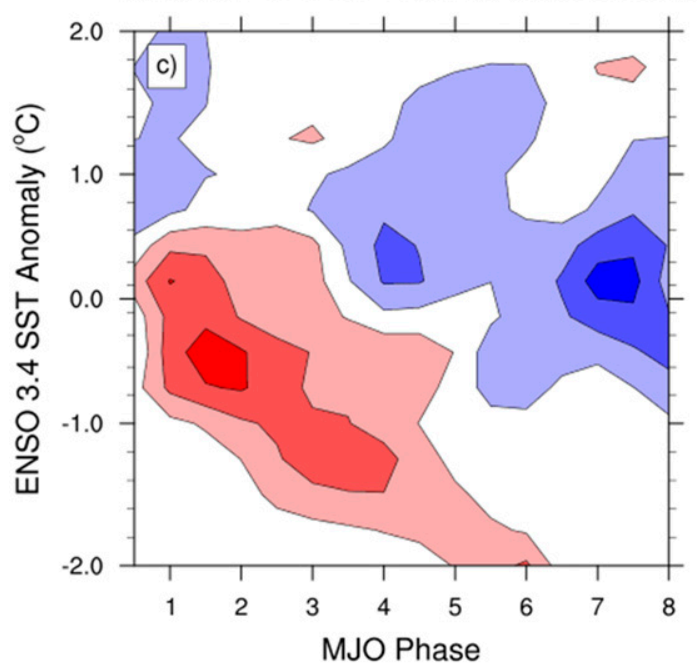

Top 10\% ACE PDF Anomaly (Weak MJO)

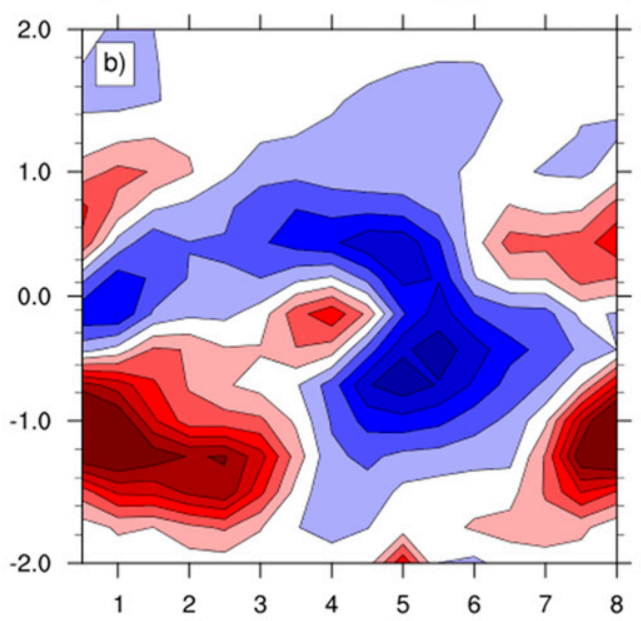

Top 10\% ACE PDF Anomaly (Strong MJO)

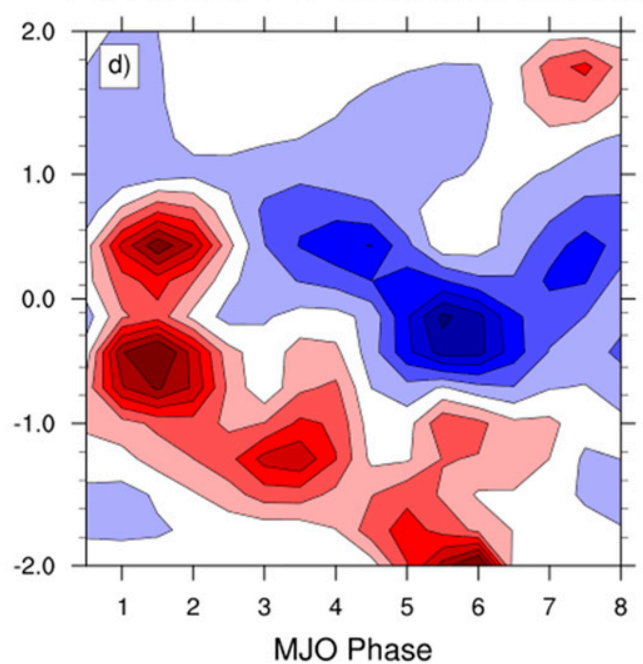

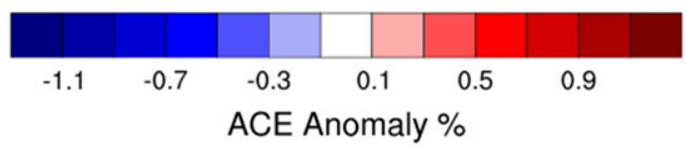

FIG. 4. Probability density function anomalies in MJO-ENSO phase space of (a) uppermost tercile of $\mathrm{ACE}_{5}^{\prime}$ events during weak MJO events, (b) uppermost decile of $\mathrm{ACE}_{5}^{\prime}$ events during weak MJO events, (c) uppermost tercile of $\mathrm{ACE}_{5}^{\prime}$ during strong $\mathrm{MJO}$ events, and (d) uppermost decile of $\mathrm{ACE}_{5}^{\prime}$ during strong $\mathrm{MJO}$ events.

are found to be largely positive for combined La Niña and MJO phases 1-2 (Fig. 6a). These anomalies are also higher in magnitude than either La Niña or MJO 1-2 considered individually (Figs. 5a,b). While the $\mathrm{GP}_{5}^{\prime}$ signal in the combined MJO and ENSO phase resembles a sum of the signals in the individual phases, some regions, notably the eastern Atlantic, have higher anomalies than one would expect with linear combinations. Conversely, $\mathrm{GP}_{5}^{\prime}$ associated with El Niño and MJO phases 5-6 are also magnified, resulting in an especially hostile environment for TC activity in the
Atlantic (Fig. 6d). The most interesting combinations occur when the MJO and ENSO counteract each other. MJO phases 5-6 appear to overwhelm the $\mathrm{GP}_{5}^{\prime}$ signal from La Niña, resulting in an Atlantic basin that is mostly hostile to development (Fig. 6b). On the other hand, MJO phases 1-2 in combination with El Niño are associated with overall neutral $\mathrm{GP}_{5}^{\prime}$ in the Atlantic (Fig. 6c). Due to spatial limitations of genesis indices, we avoid drawing conclusions about conditions in any particular subregion. Combined MJO and ENSO $\mathrm{GP}_{5}^{\prime}$ signals suggest that the MJO predominates over 

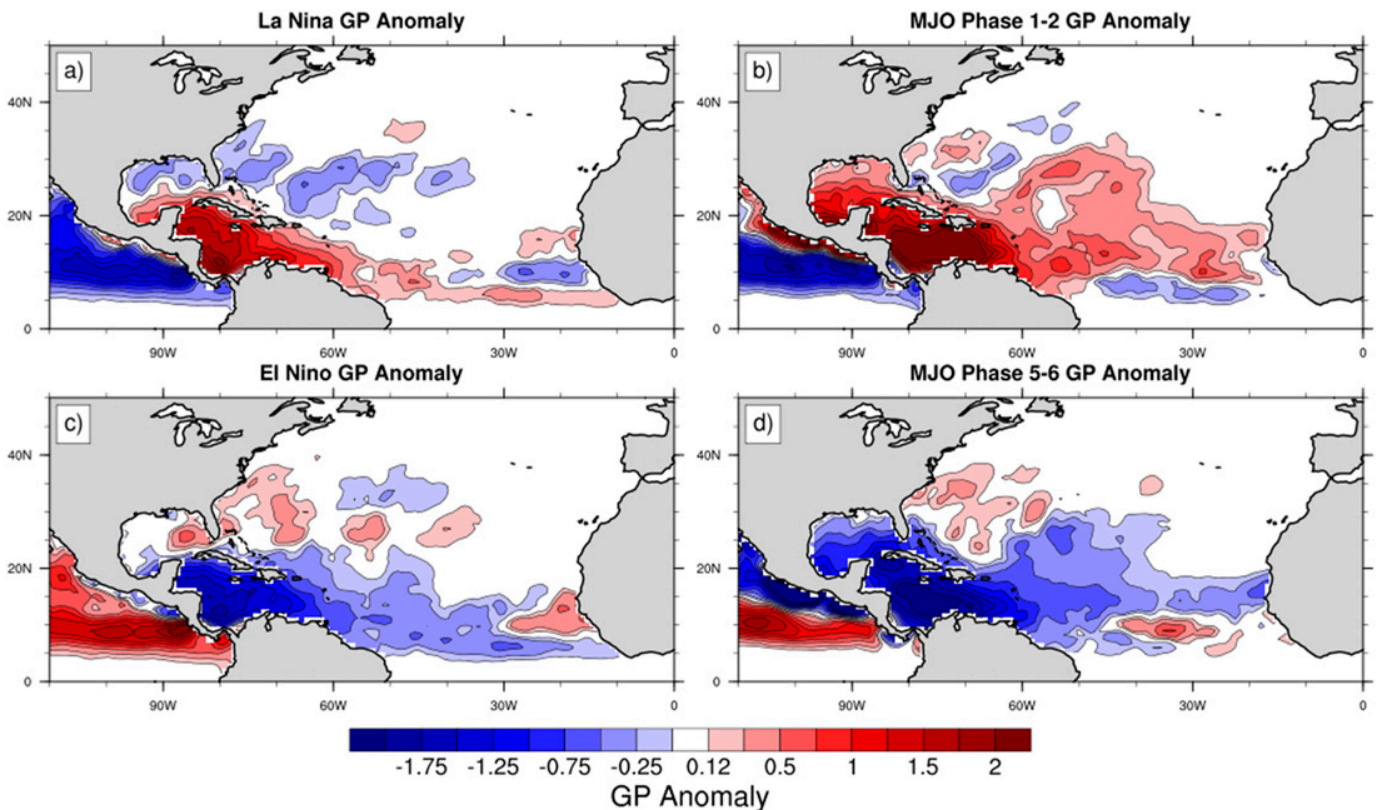

FIG. 5. Composites of $\mathrm{GP}_{5}^{\prime}$ during (a) La Niñas, (b) MJO phases 1-2, (c) El Niños, and (d) MJO phases 5-6.

ENSO in governing subseasonal Atlantic environmental conditions.

\section{Subseasonal signals using SNCR and ABY}

This section uses SNCR and ABY to find patterns of environmental parameters associated with subseasonal periods of above-average TC activity. What distinguishes this from the previous section and other works is the removal of seasonal environmental signals and using TC activity as the independent variable.

We first look at signals in the GP field to compare against those of the MJO, which is conventionally thought to be the primary mode of subseasonal variability (Janiga et al. 2018). This is done in hopes of establishing a physical mechanism in which the MJO modulates TC activity.
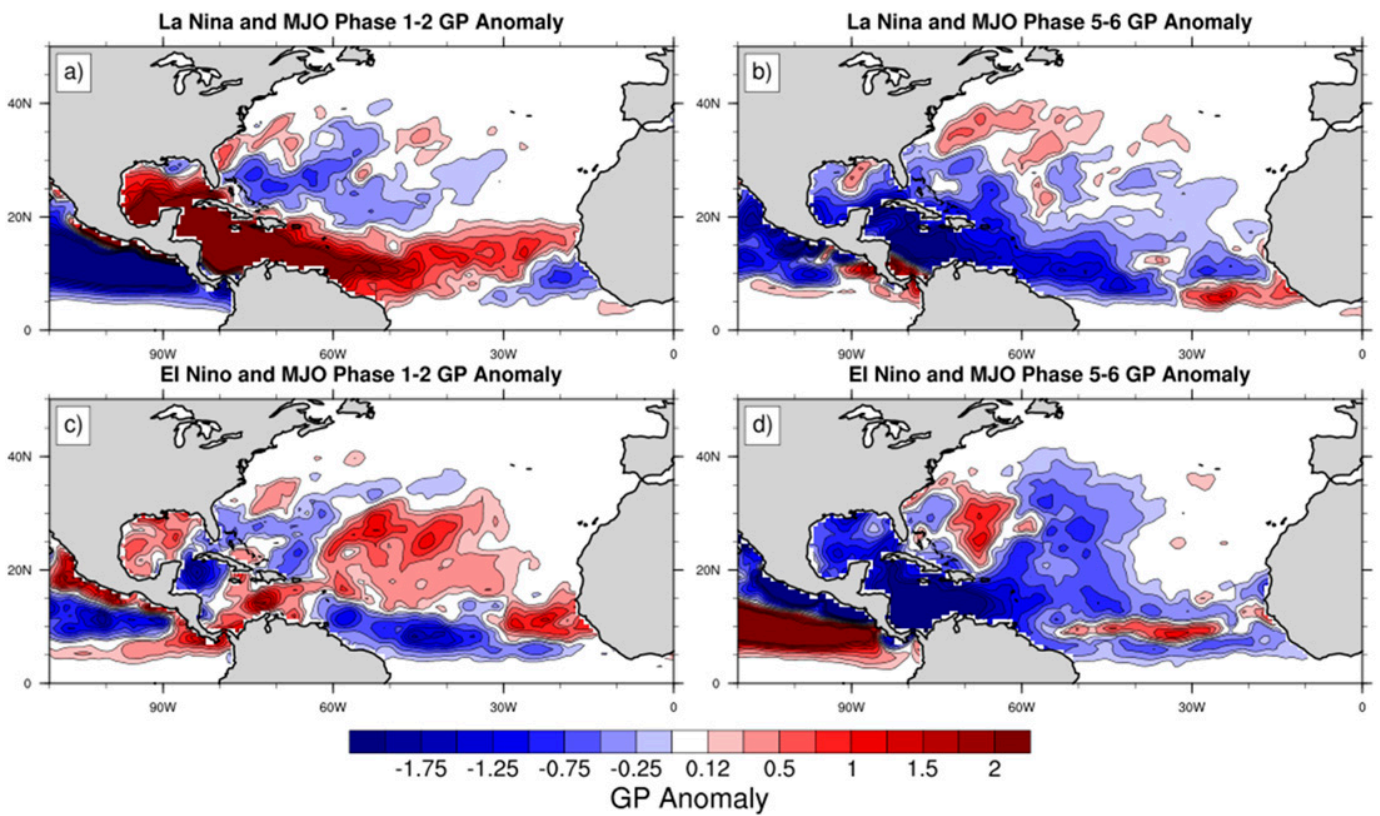

FIG. 6. Composites of $\mathrm{GP}_{5}^{\prime}$ associated with (a) La Niñas and MJO phase 5-6, (b) La Niñas and MJO phase 1-2, (c) El Niños and MJO phase 1-2, and (d) El Niños and MJO phase 5-6. 

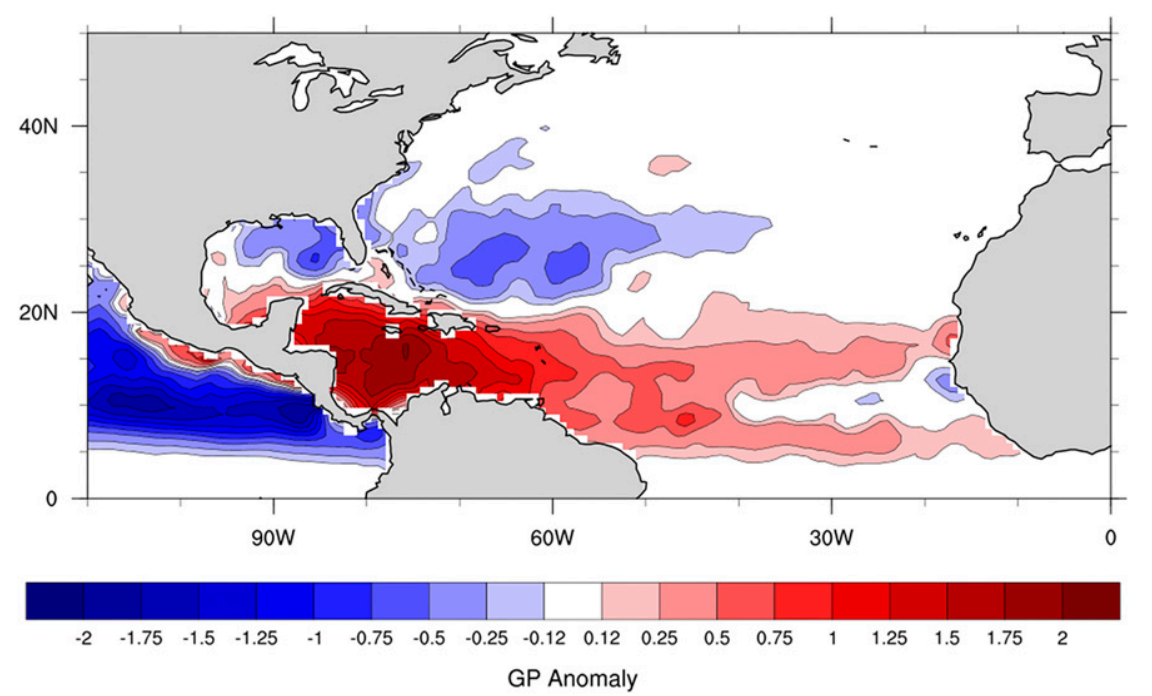

FIG. 7. Composite GP anomalies associated with the top third of Atlantic seasons measured by ACE.

The means of demonstrating a link between environmental conditions, TCs and global oscillations is first illustrated using the more well-known seasonal TC activity relationships, via a comparison between $\mathrm{GP}_{5}^{\prime}$ associated with La Niña events and $\mathrm{GP}_{5}^{\prime}$ associated with the top third of Atlantic hurricane seasons as measured by ACE. While the magnitudes of $\mathrm{GP}_{5}^{\prime}$ are somewhat higher for active seasons (Fig. 7) than for La Niña events (Fig. 5a), the spatial distribution is very similar. In fact, the anomaly correlation coefficient (ACC) of the $\mathrm{GP}_{5}^{\prime}$ in the Atlantic in association with La Niña versus seasonal Atlantic activity is 0.93 . The main area with spatial discrepancy of these anomalies is in the MDR, but this distinction could be explained by the AMO or AMM, which influences SSTs in this region (Vimont and Kossin 2007; Servain et al. 1999). Although alone this is not conclusive, this data suggests a link between ENSOproduced environmental conditions and the seasonal activity of Atlantic TCs. Given previous research showing physical mechanisms in which the ENSO state alters shear and stability in the Atlantic, it is reasonable to conclude that ENSO modulates Atlantic TC activity through changes in environmental conditions.

In a similar vein, we now compare subseasonal patterns of $\mathrm{GP}_{5}^{\prime}$ associated with subseasonal Atlantic TC activity using the SNCR and ABY methods with $\mathrm{GP}_{5}^{\prime}$ signals associated with the MJO. We would expect that these two signals would be relatively similar. However, we are unable to make such a distinctive connection. While the MJO phase has a clear $\mathrm{GP}_{5}^{\prime}$ signal over the Atlantic (Fig. 5b), no corresponding high magnitude Atlantic $\overline{\mathrm{GP}_{5}^{\mathrm{SNCR}}}$ anomalies appear to exist (Fig. 8). The lack of strong signals in association with ACE is consistent across both SNCR and ABY techniques, using both GP or TCS composites and for various temporal running means of GP and percent thresholds of SNCR and ABY (not shown).

Figure 8 implies that there is no connection between the MJO-produced environment and subseasonal TC activity, at least as measured by GP. Not only that, but $\overline{\mathrm{GP}_{5}^{\prime S N C R}}$ anomalies are near zero, if not slightly negative, on average across the Atlantic suggesting there is no consistent geographic environmental signal associated with subseasonal Atlantic TC activity. This is a counterintuitive result. Since MJO phases 1 and 2 are associated with a strong GP signal and are associated with increased subseasonal TC activity, we would expect the GP signal associated with increased subseasonal TC activity from SNCR and ABY to match that of the MJO. We would also logically expect that a more favorable environment for TC activity would be associated with enhanced subseasonal TC activity and thus positive GP anomalies would appear in the SNCR and ABY composites. From the previous section and earlier literature, we know that the MJO has a connection with TC activity and that the MJO has an influence on the environment over the Atlantic as measured by GP. However, the use of SNCR and ABY with GP are unable to reproduce the MJO signal in the Atlantic.

There are several reasons that a signal would not appear. One could be a shortcoming in the genesis indices, which were built on climatological data and may not capture variability on subseasonal time scales. This possibility has been suggested by previous studies (e.g., Wang and Moon 2017; Menkes et al. 2012). An analysis of west Pacific TC activity using SNCR/ABY and 


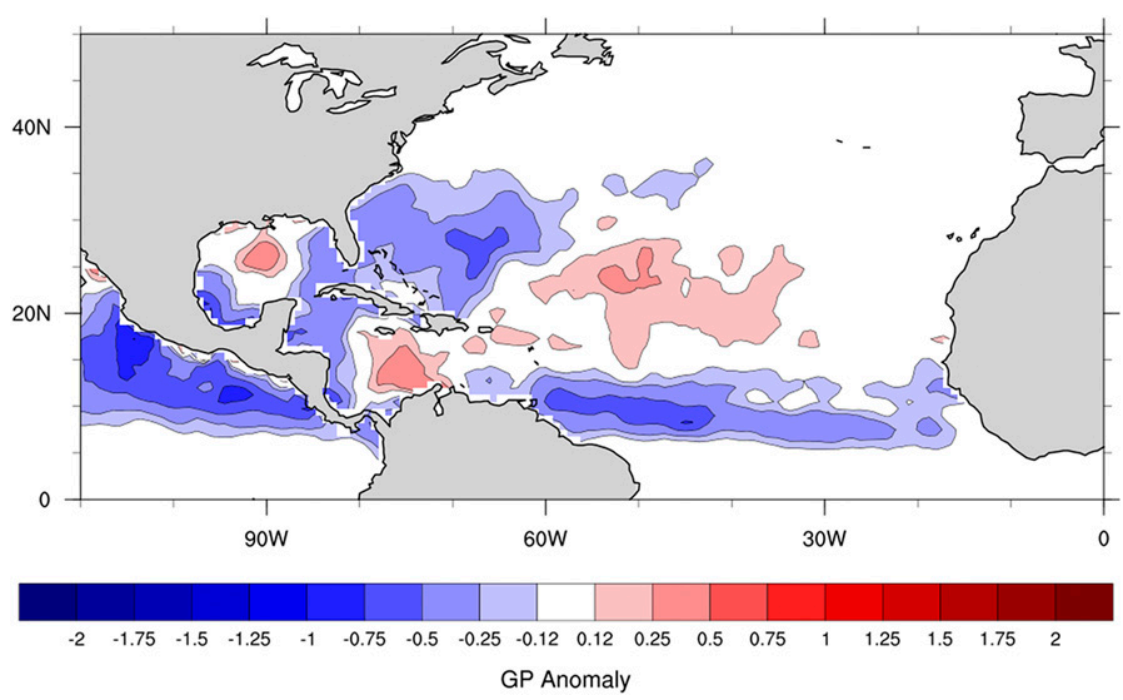

FIG. 8. Composite of $\mathrm{GP}_{5}^{\prime}$ anomalies during the top third of SNCR ACE events in the Atlantic.

GP reaffirms the shortcomings of GP on subseasonal time scales. A detailed account of this analysis is provided in appendix C. The lack of strong anomalies from SNCR and ABY could also represent a real and physical lack of subseasonal environmental signals and predictors in the Atlantic. An alternative suggestion, based on previous studies of MJO influences on AEWs (Aiyyer and Molinari 2008; Ventrice et al. 2011), is that the primary connection between the MJO and TC activity is through the AEWs themselves, whereas the modulation of the environment by the MJO may be secondary.

Regardless of the results of GP anomalies, SNCR and ABY should demonstrate the established relationship between the MJO phase and Atlantic TC activity. This can be illustrated by taking SNCR and ABY composites of global precipitation. Over the MJO convective regions (Indian Ocean and west Pacific), the top $10 \%$ Precipitation $_{5}^{\text {SNCR }}$ (Fig. 9a) is very similar to the MJO phase 1 and 2 precipitation anomalies (Fig. 9b). Even for the lower 33\% threshold for SNCR and ABY, the ACC between MJO phase 1 and 2 precipitation anomalies and Precipitation $_{5}^{\text {SNCR }}$ over the MJO convective regions is 0.57. Precipitation ${ }_{5}^{\mathrm{ABY}}$ is very similar to Precipitation $_{5}^{\mathrm{SNCR}}$ and has a similar correlation with the MJO pattern over the Maritime Continent $(r=0.55)$. The precipitation anomalies associated with SNCR and ABY are comparatively low. This is somewhat expected given the partial attenuation of the MJO signal over the Western Hemisphere and the broad sample of events used for SNCR and ABY. The La Niña precipitation pattern is shown in Fig. 9c to demonstrate that while the precipitation anomalies are similar to those of MJO phases 1 and 2 over the Atlantic, they differ in the far west Pacific and Indian Ocean. Precipitation ${ }_{5}^{\text {SNCR }}$ and Precipitation $_{5}^{\prime S N C R}$ anomalies in those regions more closely match the MJO signal, suggesting these methods are picking up the correct subseasonal source of Atlantic TC activity.

Given that SNCR and ABY detect the MJO precipitation pattern, there is still the question of why SNCR and $\mathrm{ABY}$ show little environmental subseasonal signal in the Atlantic. Part of the reason $\overline{\mathrm{GP}_{5}^{\mathrm{SNCR}}}$ and $\overline{\mathrm{GP}_{5}^{\prime \mathrm{ABY}}}$ in the Atlantic are neutral could be that some of the contributing variables have little subseasonal variability, thereby obscuring the total signal. To isolate subseasonal signals, we investigate the individual parameters of GP. Many parameters like vorticity, PI, and instantaneous RH have little meaningful signal in the SNCR and ABY analyses (see appendix D).

One parameter that does have a definite signal in association with subseasonal TC activity is vertical wind shear. The $\overline{\text { Shear }_{5}^{\text {SNCR }}}$, seen in Fig. 10, reveals that there is a signal for weaker wind shear in the Caribbean and western MDR, with a peak magnitude in the southeast Caribbean. The $\overline{\text { Shear }_{5}^{\prime \mathrm{ABY}}}$ signals (not shown) are also consistent with the pattern displayed by $\overline{\text { Shear }_{5}^{\prime S N C R}}$. Lower shear in these regions makes physical sense as weaker shear is more favorable for genesis and intensification. Complementary to the negative shear anomalies is a region of higher shear to the north, between the Bahamas and Bermuda. The shear pattern associated with subseasonal TC activity (Fig. 10) is similar to the pattern associated with MJO phases 1 and 2 (Fig. 11a). Both indicate a region of higher shear north of the Caribbean and a large area of lower shear over the 

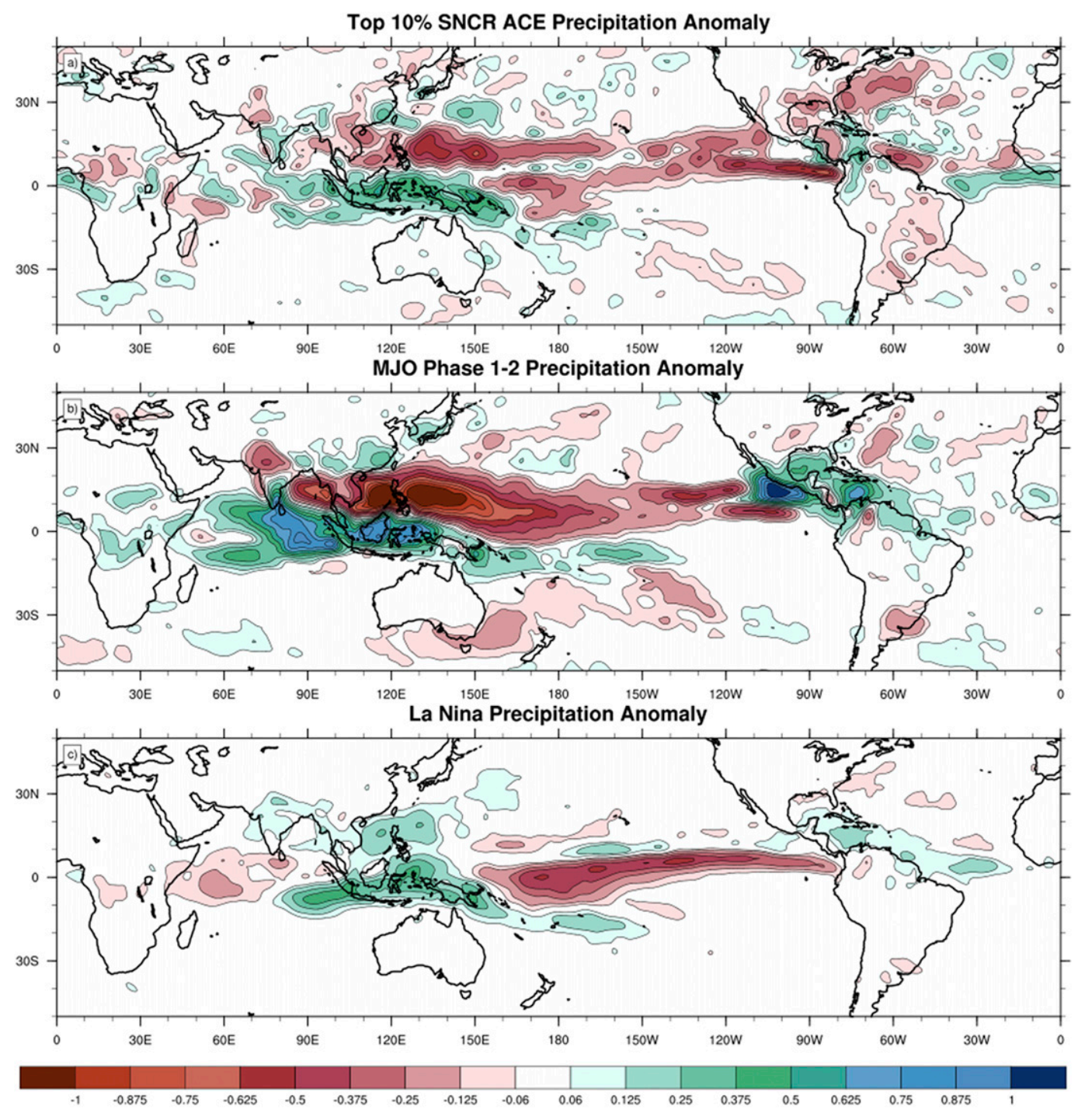

Precipitation Anomaly (mm/day)

FIG. 9. (a) Precipitation ${ }_{5}^{\prime}$ for top $10 \%$ of SNCR ACE $\mathrm{A}_{5}^{\prime}$ events in the Atlantic, (b) Precipitation ${ }_{5}^{\prime}$ during MJO phases 1 and 2, and (c) Precipitation ${ }_{5}^{\prime}$ during La Niña events.

MDR. In the Atlantic, the ACC between the MJO and $\overline{\text { Shear }_{5}^{\prime S N C R}}$ is 0.58 , and 0.54 between the MJO and $\overline{\text { Shear }_{5}^{\prime A B Y}}$ (Table 1). However, there are notable differences between the MJO and SNCR/ABY composites. The negative shear anomalies during MJO phases 1 and 2 are stronger and more widespread than the SNCR or ABY composites. Positive shear anomalies in the subtropical Atlantic are also weaker and less expansive for MJO phases 1 and 2. The primary signal from a favorable MJO is lower shear in the tropical Atlantic. While the signal in association with subseasonal TC activity also exhibits lower shear in the MDR, the positive shear anomalies in the midlatitudes (just to the north) appears equally important, and this dipole structure may be a crucial predictor independent of the MJO.

To further assess the relationship between subseasonal $\mathrm{TC}$ activity and the MJO, the $\overline{\text { Shear }_{5}^{\prime A B Y}}$ composites are separated by MJO phase. Shear anomalies associated with MJO phases 1 and 2 are nearly the inverse of MJO phases 5 and 6 (Figs. 11a,b). The composites of combined MJO phase and $\overline{\text { Shear }} 5$ nated by the MJO patterns (Figs. 11c,d). In other words, for active TC periods during unfavorable MJO phases, the shear is still higher than normal over most of the MDR. Figures 11e and 11f show the difference between 

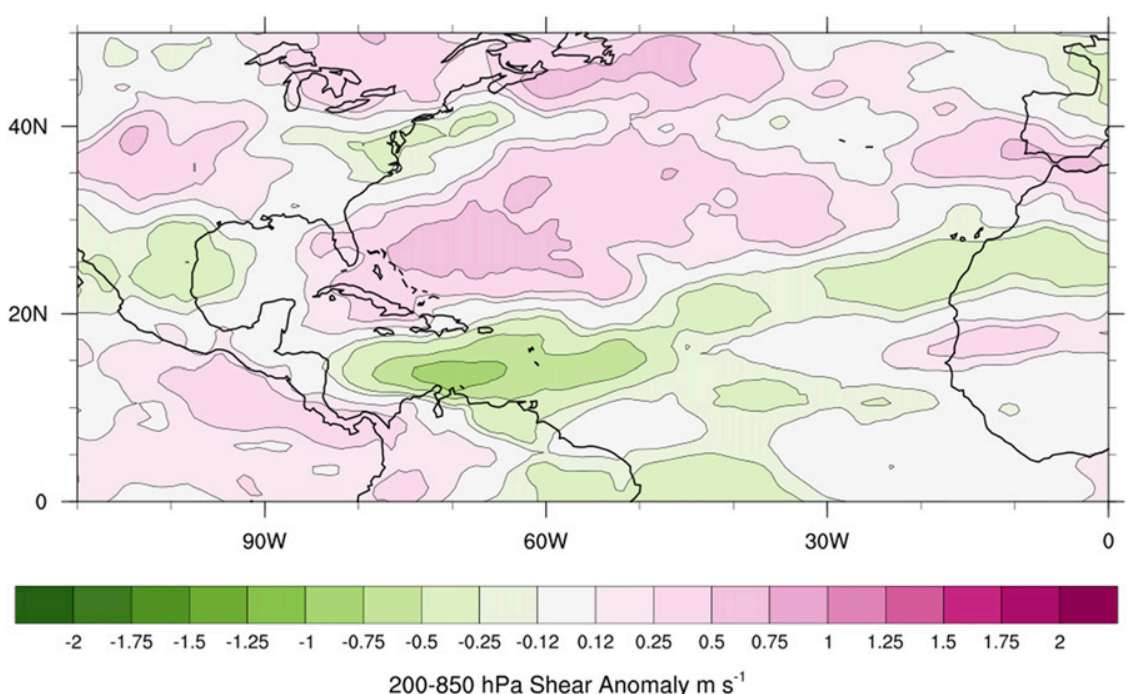

FIG. 10. Composite of Shear' anomalies during the top third of ABY events in the Atlantic $\left(\overline{\text { Shear }_{5}^{\prime A B Y}}\right)$.

the combined MJO-ABY composites and the pure MJO composites, or Fig. 11c minus Fig. 11a and Fig. 11d minus Fig. 11b, which can be thought of as the anomaly of $\overline{\text { Shear }_{5}^{\prime A B Y}}$ with respect to the MJO base state. In both of these figures, the Shear ${ }_{5}^{\prime A B Y}$ relative to the MJO shows lower shear in the western MDR and eastern Caribbean and higher shear in most of the subtropical Atlantic. There are some differences between shear patterns for different phases of the MJO. In Fig. 11f, shear anomalies with respect to MJO phases 5 and 6 are slightly higher in magnitude, likely indicating that conditions need to (at least somewhat) compensate for the high shear of the background MJO state. The center of the lowest shear anomalies is also shifted zonally by MJO phase with the favorable MJO having the lowest shear in the western MDR during active subseasonal TC periods (Fig. 11e). Negative shear anomalies peak in the Caribbean for active periods during unfavorable MJO phases (Fig. 11f), although given the small number of cases this distinction may not be a meaningful physical signal.

The similarity of these anomalies with respect to different MJO phases suggests that there is a signal in shear other than that from the MJO that is important for subseasonal Atlantic TC activity. Lower shear over the Caribbean and MDR makes physical sense as it would directly translate to a more favorable environment for TC activity. However, the high shear signal in the subtropical Atlantic also appears to be an important feature. In fact, where most SNCR and ABY signals of all other parameters are comparatively weak, the positive shear anomalies in $\overline{\text { Shear }_{5}^{\prime A B Y}}$ are greater in magnitude than the positive shear anomalies associated with a favorable MJO phase. Extratropical interactions could be the cause of this positive shear anomaly, and this will be discussed further in the conclusion.

There is no definite environmental signal of $\overline{\mathrm{RH}_{5}^{\prime \mathrm{ABY}}}$ during active TC periods as shown in appendix D; however, the signal may be removed temporally, potentially preceding active periods as suggested by Maloney and Shaman (2008). To account for this, $\mathrm{RH}_{5}^{\prime A B Y}$ is recalculated using a composite of $\mathrm{RH}$ anomalies preceding peak ACE by 10 days, as opposed to the original of no lag (i.e., $i \mathrm{ABY}$ are shifted to $i \mathrm{ABY}-10$ ). Using lagged $\mathrm{ABY}$, the $\mathrm{RH}$ anomalies in the tropical Atlantic are found to be generally weak (Fig. 12). However, there are a few areas with high $\mathrm{RH}$ anomalies to note, some of which are more substantial than the instantaneous anomalies in Fig. D2b. High RH anomalies over West Africa could indicate a reduction of low humidity air associated with the Saharan air layer (SAL) prior to active periods. Previous studies have suggested that the SAL impedes Atlantic TC activity, especially earlier in the season (Dunion and Velden 2004). Another region with high RH anomalies is along the U.S East Coast. This region is associated with frontal systems, and increased RH anomalies here may indicate increased extratropical activity. This would agree generally with the analysis of the $\overline{\text { Shear }_{5}^{\prime S N C R}}$ anomalies. Finally, a region of higher RH anomalies appears around the west coast of Mexico. This is also where the strongest RH signals occur in association with the favorable MJO phases, thus the MJO may be linked to environmental conditions through $\mathrm{RH}$.

While RH anomalies in these regions are comparatively high, $1.25 \%$, we are not sure this reflects a physically 

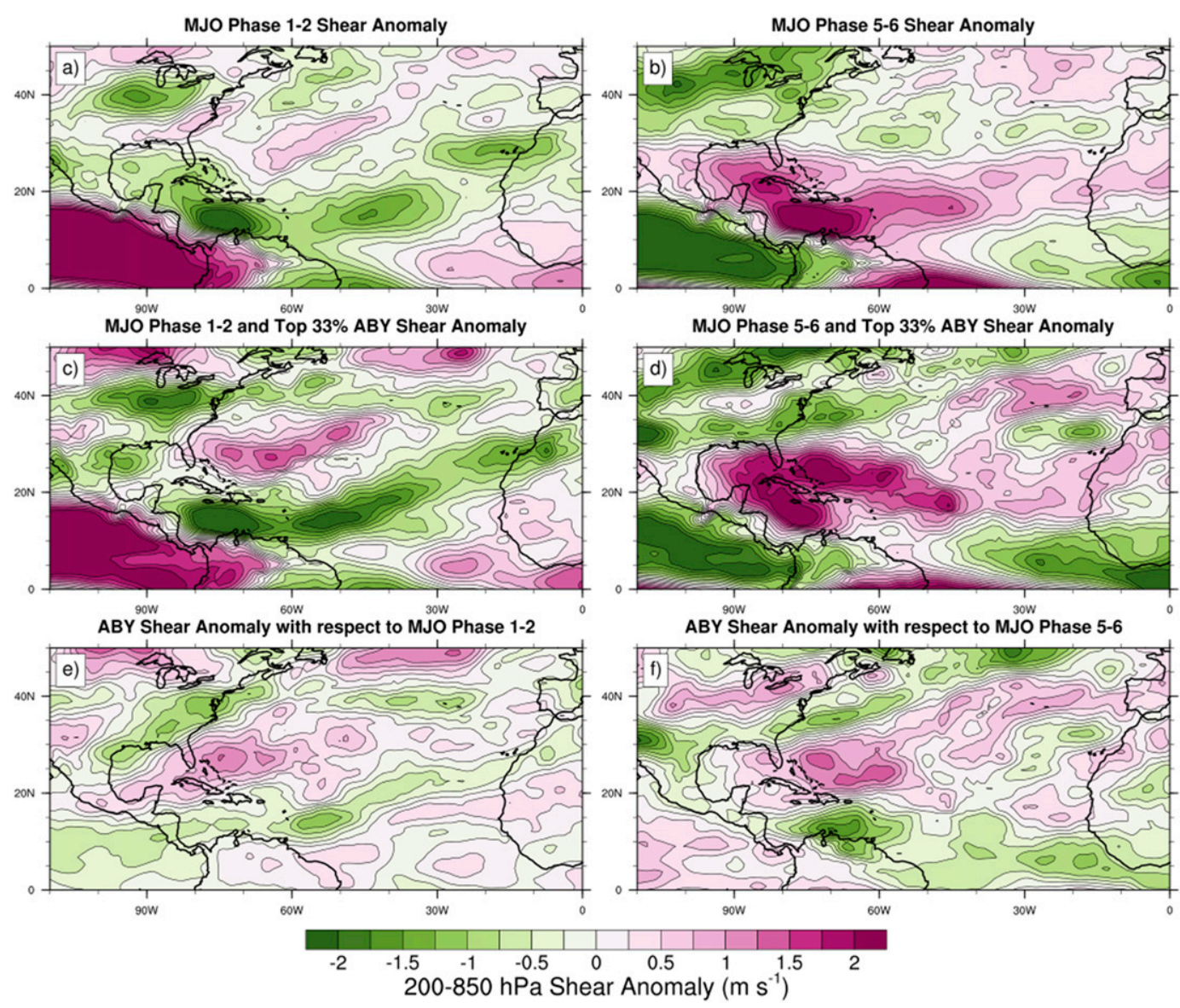

FIG. 11. Composite of shear anomalies during (a) strong MJO phases 1 and 2, (b) strong MJO phases 5 and 6 , (c) strong MJO phases 1 and 2 and top 33\% of ABY events, (d) strong MJO phases 5 and 6 and top 33\% of ABY events, (e) panel (c) minus (a), and (f) panel (d) minus (b).

meaningful relation. ${ }^{4}$ Other anomalies of similar magnitude occur in seemingly unrelated regions of the globe (not shown), and all anomalies are relatively small in comparison to the MJO (Fig. D2a). Hopefully, in the future, with longer observation periods, real signals will become more apparent.

\section{Discussion and conclusions}

The Atlantic basin has large fluctuations in TC activity on subseasonal time scales. Prediction of TC activity beyond 7 days is conventionally delegated to MJO forecasts, or cautiously to unproven long-range weather models. Both forecast methods currently lack accuracy for several reasons, including the models' limited ability to accurately represent physical characteristics

\footnotetext{
${ }^{4} n=227 ; 95 \%$ confidence interval: from $+0.3 \%$ to $2.7 \%$; $p=0.02$.
}

of the MJO or TCs. We suggest that a better understanding of the mechanisms behind subseasonal TC activity is needed, in order to isolate and prioritize the main sources of subseasonal forecast error. This study has identified both MJO-ENSO patterns and environmental signals in the Atlantic basin that can be used to provide potential indicators of TC activity to be used by dynamical models on subseasonal time scales.

The first part of this study analyzed interactions of ENSO and the MJO with Atlantic TC activity. Both phenomena individually have well-established connections with TC activity in the Atlantic basin and Klotzbach and Oliver (2015a) have established nonlinear connections between ENSO and MJO with Atlantic TC activity and environments; but the combined influence of these events is still not known comprehensively. By examining a continuous spectrum on MJO-ENSO phases, we are able to find a shift in favorable MJO phase with change in ENSO phase. 
TABLE 1. Anomaly correlation coefficients between MJO phase 1 and 2 with Atlantic SNCR ACE and ABY composites of anomalies of several parameters (column 1) across different regions (row 1). ACC values greater than 0.5 are bolded. Qualitative discussion of the magnitude of the anomalies in the Atlantic is listed in the far right-hand column.

\begin{tabular}{lccccc}
\hline \hline ACC of MJO phase 1 and 2 & Atlantic & Global tropics & Tropical IO + WPAC & $\begin{array}{c}\text { Magnitude of } \\
\text { anomalies in Atlantic }\end{array}$ \\
\hline GP & SNCR & 0.29 & 0.40 & 0.50 & Low \\
\multirow{2}{*}{ Shear } & ABY & 0.23 & 0.36 & 0.48 & Low \\
& SNCR & $\mathbf{0 . 5 8}$ & 0.45 & $\mathbf{0 . 6 6}$ & High \\
RH & ABY & $\mathbf{0 . 5 4}$ & 0.33 & $\mathbf{0 . 6 6}$ & High \\
& SNCR & -0.10 & 0.38 & 0.46 & Medium \\
Vorticity & ABY & -0.14 & 0.30 & 0.38 & Medium \\
\multirow{2}{*}{ SST } & SNCR & $\mathbf{0 . 5 1}$ & 0.34 & 0.49 & Low \\
& ABY & 0.49 & 0.29 & $\mathbf{0 . 5 6}$ & Low \\
Precipitation & SNCR & $\mathbf{0 . 5 8}$ & $\mathbf{0 . 5 1}$ & $\mathbf{0 . 5 3}$ & Very low \\
& ABY & 0.33 & 0.38 & $\mathbf{0 . 5 7}$ & Very low \\
& SNCR & 0.08 & 0.34 & $\mathbf{0 . 5 5}$ & Low \\
\hline
\end{tabular}

Our results reinforce the notion that strong El Niños produce an unfavorable environment that favorable MJOs are unable to overcome. However, for periods of weak warm ENSO anomalies, which are more common, MJO phases 1 and 2 are associated with increased TC activity in the tropical Atlantic. For La Niñas and strong MJO events there tends to be more variability in TC activity with $\mathrm{MJO}$ phase. It therefore appears that $\mathrm{La}$ Niñas set up a background environment that the MJO can overcome. While this hypothesis generally holds, it is overly simplistic and certain patterns in MJO-ENSO interactions defy this explanation. For instance, there appears to be a consistent shift in favorable MJO phase with the ENSO state. As noted in Figs. $4 \mathrm{c}$ and $4 d$, the most active MJO phases are 1 and 2 for neutral ENSO conditions. However, for moderate La Niñas the MJO phases most likely to experience increased TC activity are phases 3 and 4 and for strong La Niñas this shifts to phases 5 and 6.

The combination of environmental signals of MJO and ENSO provides a plausible explanation for some of the observed trends in TC activity. Strong El Niños are largely associated with negative genesis potential (GP) anomalies in the tropical Atlantic, even during MJO phases 1 and 2. On the other hand, favorable environmental conditions associated with La Niña as measured by GP can be completely counteracted by MJO phase, which is consistent with the higher variability in TC activity with MJO during cold ENSO events. However, GP anomalies during warm ENSO events and favorable

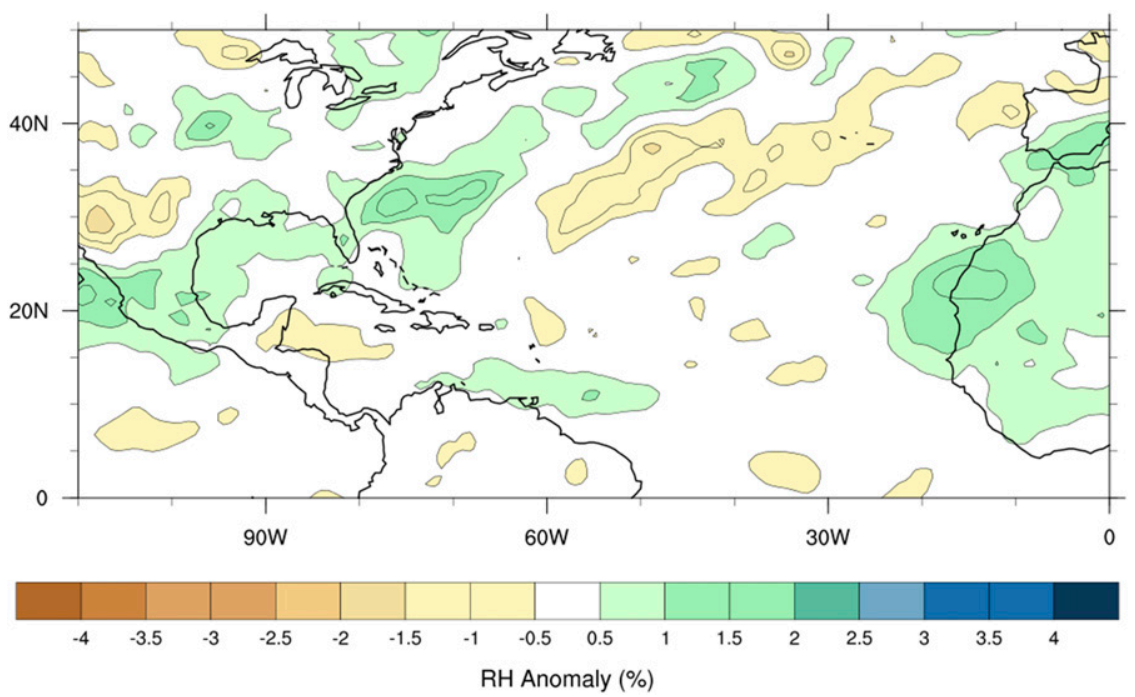

FIG. 12. Composite of RH anomalies from 10 days preceding the top $33 \%$ of $i \mathrm{ABY}$ days. 
MJO phases tend to be near zero, suggesting that MJO and ENSO have a nearly equal influence on the environment while previous research had suggested that El Niño should dominate (Klotzbach and Oliver 2015b). It is important to note that while GP attempts to offer a plausible explanation of the general pattern of MJOENSO combined influences on TC activity, GP in fact does not capture the shift in favorable MJO phase or other deviations from the general trends in TC activity. GP has also appeared unreliable in diagnosing activity in other basins, and these results should be viewed skeptically.

To assess other possible influences on subseasonal Atlantic TC activity, and in an attempt to solidify understanding of the MJO influence on TC activity, two methods, SNCR and ABY, were developed. SNCR and $\mathrm{ABY}$ evaluate subseasonal variability of GP and other parameters with TC activity by taking selective composites of environmental fields. While the MJO has a clear influence on environmental conditions in the Atlantic, the GP anomalies associated with subseasonal TC activity is near zero. There are several explanations for this. One is that the MJO influences TC activity in means that are not measured by the GP. Other environmental parameters like vertical motion (Wang and Moon 2017) are found to be important on subseasonal time scales and a variety of other environmental parameters such as upper-level temperature and divergence are important for TC intensification (DeMaria and Kaplan 1999). The MJO has also been shown to influence AEW strength (Aiyyer and Molinari 2008) and may modulate TC activity through incipient disturbances rather than the TC environment. The lack of an environmental signal associated with subseasonal TC activity could be due to a flaw in the metrics for our application. Since GP (and TCS) are based on climatological data, they miss patterns associated with mesoscale storms, and the combination of multiple parameters obscures the signals of individual parameters. Finally, environmental conditions that favor TC activity may be localized to the region around the TC itself, making composites over fixed locations ineffective at capturing the important environmental signals.

Although subseasonal TC activity was not expressed in the GP fields, there is a signal in vertical shear and, to a lesser extent, RH. Positive RH anomalies exist days before active periods over western Africa and off of the southeast U.S. coastline. Moist anomalies over western Africa may indicate an absence of the Saharan air layer. RH anomalies off of the eastern United States could be in association with frontal systems. The relationship between troughs and TCs is complicated but trough interactions aid in about $20 \%$ of TC genesis cases (McTaggart-Cowan et al. 2013) and can favor strengthening under certain conditions (Hanley et al. 2001). Consistent with, and stronger than the positive $\mathrm{RH}$ anomalies is enhanced vertical shear anomalies in the same region. This provides further evidence of the importance of midlatitude interactions. In addition to collocated positive shear and RH anomalies, shear also exhibits negative anomalies in the eastern Caribbean and Main Development Region in association with subseasonal TC activity. This pattern generally matches that of the favorable MJO phase. The combination of enhanced troughs and MJO phase 1 and 2 shear patterns could explain the shear pattern produced in association with subseasonal TC activity.

While it is known that the MJO influences TC activity and atmospheric conditions, we were unable to identify a clear connection between the MJO-produced environment and the environment associated with subseasonal TC activity. However, SNCR and ABY implicate two other phenomena that could possibly influence subseasonal TC activity: the Saharan air layer and trough interactions in the west Atlantic.

\section{Future work}

Climate models used for subseasonal prediction currently have poor rendering of TCs and their climatology (Camargo 2013). If there is a robust signal in subseasonal predictors such as the Saharan air layer or vertical wind shear, there is a possibility that skill can be achieved without the need for accurate TC representation. Testing the use of the most effective environmental indicators for subseasonal TC prediction and then testing the model skill in predicting these environmental indicators may prove to be useful in making accurate predictions, or at the very least provide a predictive method with a spatially and temporally continuous verification.

One curious finding came from testing SNCR. Figure 13 shows composites of GP anomalies with the Atlantic average SNCR GP. Unsurprisingly, the whole Atlantic has a positive anomaly, and the Caribbean and MDR are highlighted as especially important regions. What is intriguing is that there are substantial anomalies in other basins. The West and east Pacific have negative anomalies of GP with roughly one fourth the magnitude of Atlantic anomalies. The Indian Ocean GP is positively correlated with Atlantic GP. The total global GP anomaly pattern very closely matches GP anomalies with MJO phases 1 and 2. This study has shown the difficulty in finding environmental signals associated with TC activity. However, the environmental 

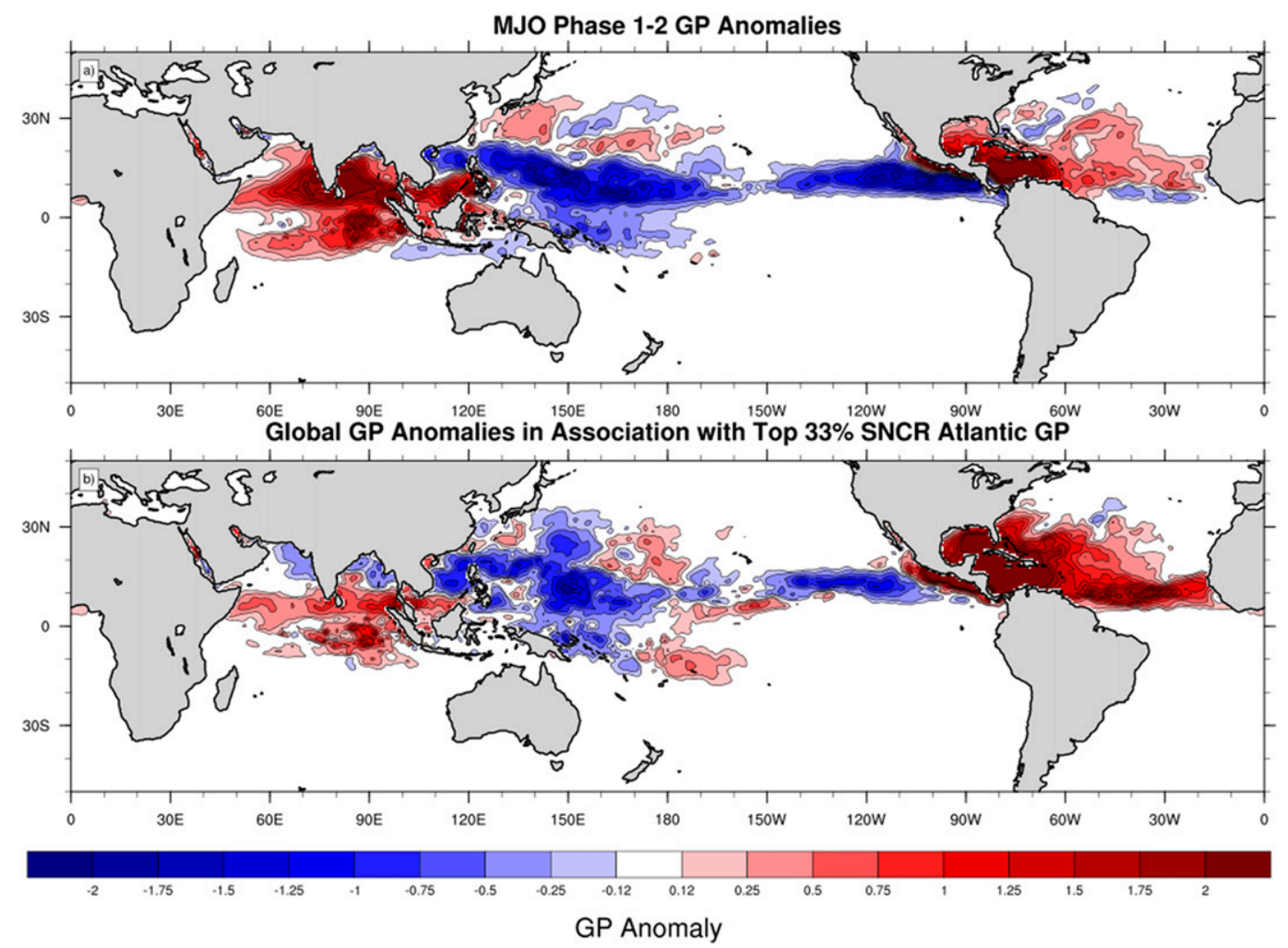

FIG. 13. Global GP anomalies associated with (a) MJO phases 1-2 and (b) SNCR composites anchored on Atlantic average GP.

conditions in the Atlantic, even once the interannual variability is removed, show strong ties to conditions in other basins and generally resolve the pattern of interbasin connections (Frank and Young 2007).

Acknowledgments. Kurt Hansen gratefully acknowledges the receipt of a University of Miami Graduate Fellowship. I would like to thank the two reviewers as well as the editor for their helpful comments that improved the manuscript. Discussions with David Nolan, Kathleen Pegion, and Marybeth Arcodia were helpful in sharpening the study.

\section{APPENDIX A}

\section{Comparison of Genesis Indices}

The Tippett Camargo Sobel index (TCS; Tippett et al. 2011) is compared against GP to evaluate whether there is general agreement (and validity) of genesis indices on subseasonal time scales. TCS is defined as

$$
\begin{aligned}
\mathrm{TCS}= & \exp \left\{b+b_{\eta} \eta+b_{\mathrm{RH}} \mathrm{RH}+b_{T} T^{\prime}\right. \\
& \left.+b_{V_{\text {shear }}} V_{\text {shear }}+\log [\cos (\phi)]\right\},
\end{aligned}
$$

where $\eta, \mathrm{RH}$, and $V_{\text {shear }}$ are the same as in GP; and $T^{\prime}$ is the difference between the local SST and tropical average SST. The last term is an area adjustment for latitude. The " $b$ " coefficients are calculated empirically from the Poisson regression of each variable onto the number of TC genesis events (Tippett et al. 2011). TCS gives the expected number of TC genesis events for a monthlong period.

This study uses $\mathrm{GP}_{5}^{\prime}$ to evaluate the total favorability of environmental conditions for TC activity. However, in order to make GP consistent with TCS, 30-day running means of the components of GP are taken before applying the GP equation:

$$
\mathrm{GP}^{30} \equiv \mathrm{GP}\left(\text { day, year, lat, lon; } \eta_{30}, \mathrm{RH}_{30}, \mathrm{PI}_{30}, V_{\text {shear }, 30}\right) \text {, }
$$

$$
\begin{aligned}
& \left.\mathrm{GP}^{\prime 30} \text { (day, year, lat, lon }\right) \\
& =\frac{\mathrm{GP}^{30}(\text { day, year, lat, lon })-\mathrm{GP}_{\text {climo }}^{30}(\text { day, lat, lon })}{\mathrm{GP}_{\text {sdev }}^{30}(\text { day, lat, lon })}
\end{aligned}
$$

$\mathrm{TCS}^{30} \equiv \mathrm{TCS}$ (day, year, lat, lon; $\left.\eta_{30}, \mathrm{RH}_{30}, \mathrm{PI}_{30}, V_{\text {shear }, 30}\right)$, 

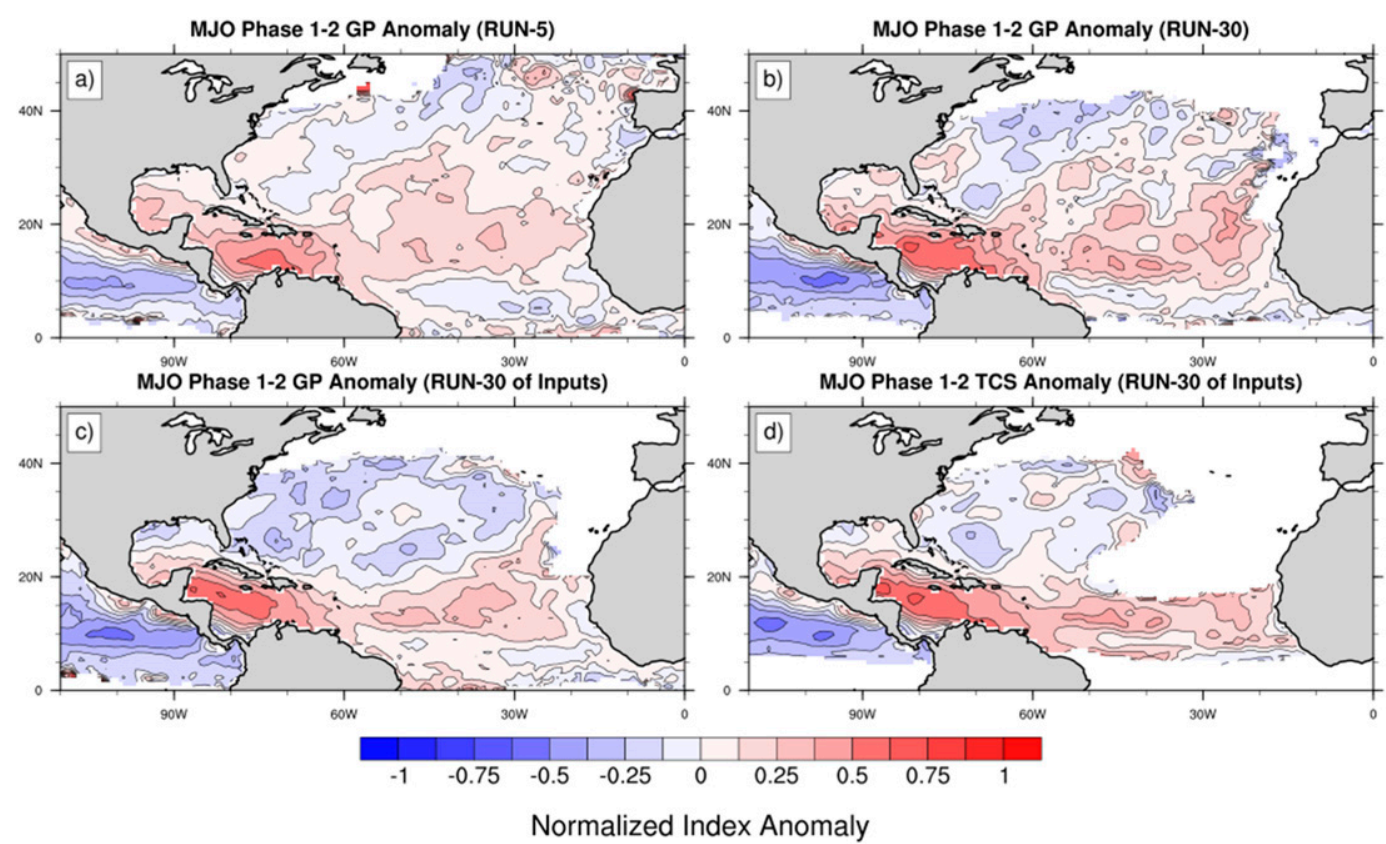

FIG. A1. (a) The 5-day running mean of GP associated with MJO phases 1 and 2, (b) 30-day running mean of GP associated with MJO phases 1 and 2, (c) GP associated with MJO phases 1 and 2 with 30-day running mean of the four environmental parameters taken prior to input of the GP equation, and (d) TCS associated with MJO phases 1 and 2. [The 30-day running mean of parameters taken prior to input of TCS equation as specified by Tippett et al. (2011).]

$$
\begin{aligned}
& \mathrm{TCS}^{\prime 30}(\text { day, year, lat, lon }) \\
& \quad=\frac{\operatorname{TCS}^{30}(\text { day, year, lat, lon })-\mathrm{TCS}_{\text {climo }}^{30}(\text { day, lat, lon })}{\operatorname{TCS}_{\text {sdev }}^{30}(\text { day, lat, lon })} .
\end{aligned}
$$

The superscript 30 refers to the fact that 30 -day running means are taken of the environmental variables first, before $\mathrm{GP}^{30}$ and $\mathrm{TCS}^{30}$, their climatological values, standard deviations, and anomalies are computed. The $\mathrm{GP}_{5}^{\prime}$ (Fig. A1a) and TCS anomalies (Fig. A1d) in association with MJO phases 1 and 2 are very similar. Some of the discrepancies in the analysis come from the length and order of the running means (Figs. A1b,c). Both genesis indices demonstrate considerable agreement on basin scales and subbasin scales, suggesting that composite analyses of subseasonal events using GP represents physical signals on these scales. However, we do not conclude this to be true for smaller regions.

\section{APPENDIX B}

\section{Verifying SNCR and ABY}

To examine whether SNCR and ABY effectively remove the influence of seasonal and climate oscillations such as ENSO, composites of east Pacific SST anomalies are taken in association with subseasonal Atlantic TC activity, as measured by SNCR and ABY. As seen in Fig. B1a, active TC seasons are associated with a cold anomaly of $1^{\circ} \mathrm{C}$ in the equatorial east Pacific indicative of a La Niña episode, which is consistent with previous studies (e.g., Gray 1984; Klotzbach and Gray 2003). The composite SST anomalies associated with ABY (Fig. B1c) peak at about $0.15^{\circ} \mathrm{C}$ in the equatorial east Pacific. Composite SST anomalies associated with SNCR (Fig. B1d) are slightly higher in magnitude peaking at $0.20^{\circ} \mathrm{C}$. MJO SST anomalies (Fig. B1b) are about $0.20^{\circ} \mathrm{C}$ along the equatorial east Pacific although higher anomalies are found off the southern Mexican coast. These magnitudes are consistent with Maloney and Kiehl (2002). Both SNCR and ABY SST anomalies are no larger than the corresponding composite SST anomalies during MJO phases 1 and 2. Given that SNCR and ABY SST anomalies are less than those of the MJO, we suggest that SNCR and ABY are successful in removing the influence of ENSO, and likely other seasonal or longer-scale influences.

The ability of SNCR and ABY to capture subseasonal signals is now demonstrated using known subseasonal connections involving different $\mathrm{MJO}$ phases in the Indian Ocean. MJO phases 1 and 2 are found to be 

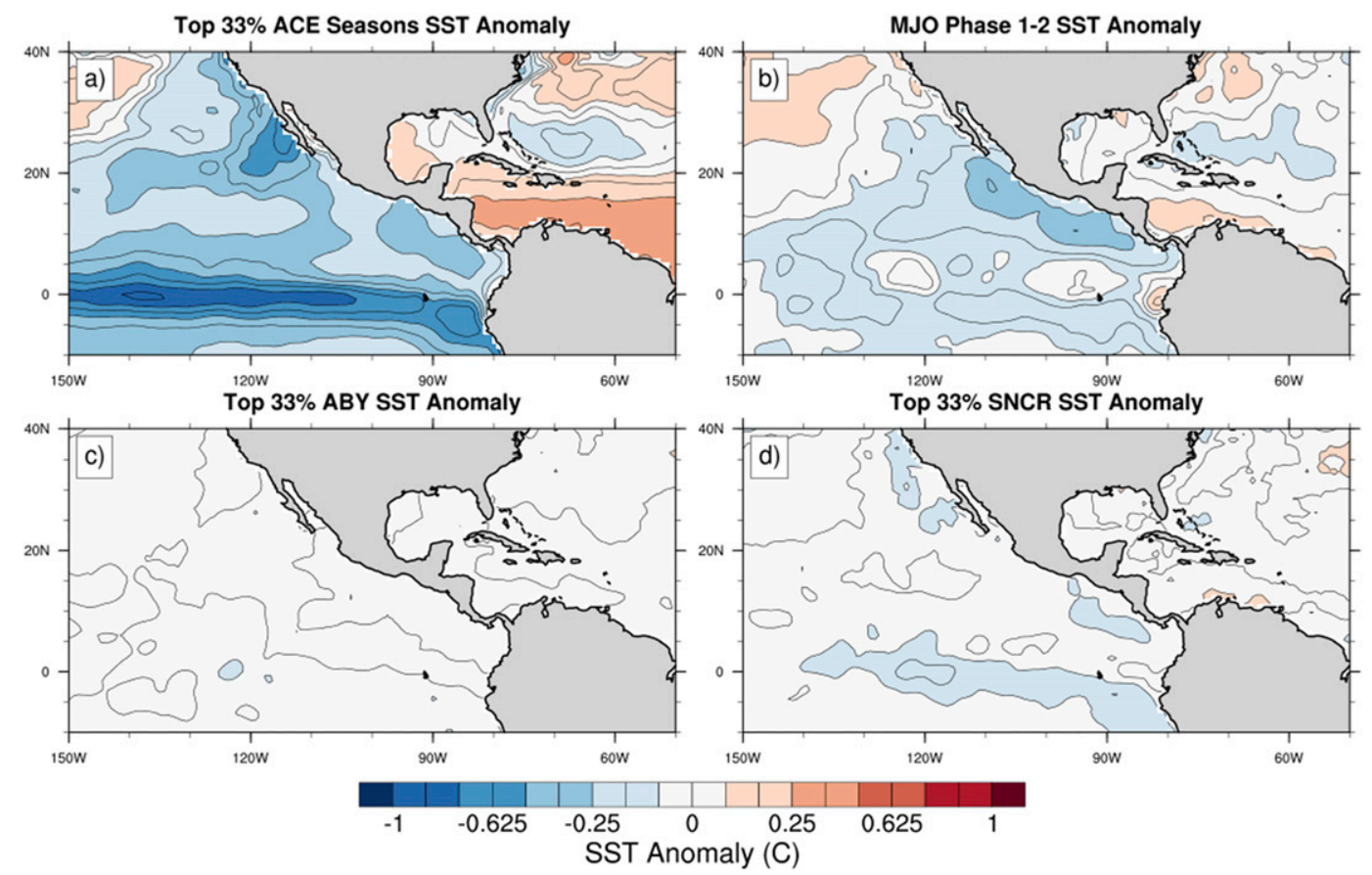

FIG. B1. (a) SST anomalies associated with the top 33\% of most active Atlantic seasons by ACE, (b) SST anomalies associated with MJO phases 1 and 2, (c) $\overline{\mathrm{SST}_{5}^{\prime \mathrm{ABY}}}$, and (d) $\overline{\mathrm{SST}_{5}^{\prime S N C R}}$.

associated with a 200-hPa zonal wind pattern in Fig. B2a, which is broadly characterized by easterlies over the Maritime Continent (MC) and westerlies over the east Pacific. These MJO phases are also known to be strongly correlated with precipitation over the Indian Ocean and MC (Zhang 2005). Area-average precipitation over the $\mathrm{MC}$ is used to create the "anchoring" variable for ABY and SNCR (as opposed to Atlantic average ACE). The 200-hPa wind anomalies are then calculated for the top third of SNCR and ABY precipitation events (Figs. B2b,c). The zonal wind anomalies in Figs. B2b and $\mathrm{B} 2 \mathrm{c}$ are found to be spatially similar to those in Fig. B2a. The anomaly correlation coefficient (ACC) of 200-hPa zonal wind anomalies in the global tropics between ABY and MJO phases 1 and 2, and between SNCR and MJO phases 1 and 2 are very high, 0.86 and 0.89 , respectively. The magnitudes of the SNCR and ABY anomalies are also large, greater than $1.5 \mathrm{~m} \mathrm{~s}^{-1}$ over vast portions of the tropics. ${ }^{\text {B1 }}$ This demonstrates that ABY and SNCR are largely able to capture subseasonal variability of precipitation associated with the MJO. Anchoring SNCR and ABY to precipitation over the Central Pacific replicated zonal wind anomalies associated with MJO phases 5 and 6 , which yielded slightly lower but still high ACC values of 0.61 and 0.71 .

\footnotetext{
${ }^{\mathrm{B} 1} n=227 ; 95 \%$ confidence interval: $0.5-1.5 \mathrm{~m} \mathrm{~s}^{-1} ; p=0.005$.
}

The 200-hPa wind anomalies computed using the ABY and SNCR techniques are smaller in magnitude than those associated with the MJO. This is because they are designed to capture all variability on subseasonal time scales, which will inevitably include noise. Deviations of ABY and SNCR signals from those of the MJO do not necessarily reflect a weakness of the methods, but (ideally) are capturing the variability in association with other subseasonal phenomena.

\section{APPENDIX C}

\section{Use of GP with SNCR and ABY}

In the western North Pacific basin (WPAC) there is considerably more TC activity and a clearer physical connection with the MJO, which will provide a simpler example to test the veracity of the SNCR and ABY methods. From our analysis, MJO phases 6 and 7 are most active in this basin. In Fig. $\mathrm{C} 1$, the $\mathrm{GP}_{5}^{\prime}$ associated with MJO phases 6 and 7 greatly resembles the west Pacific $\overline{\mathrm{GP}_{5}^{\prime S N C R}}$. In fact, as seen in Table $\mathrm{C} 1$, the ACC of normalized $\mathrm{GP}_{5}^{\prime}$ of MJO and SNCR is 0.72 in the WPAC and 0.70 in the global tropics. The ACC of the MJO pattern with WPAC $\overline{\mathrm{GP}_{5}^{\prime A B Y}}$ is similar although slightly smaller: 0.66 and 0.62 for the WPAC and the global tropics, respectively. The high spatial correlation of the 

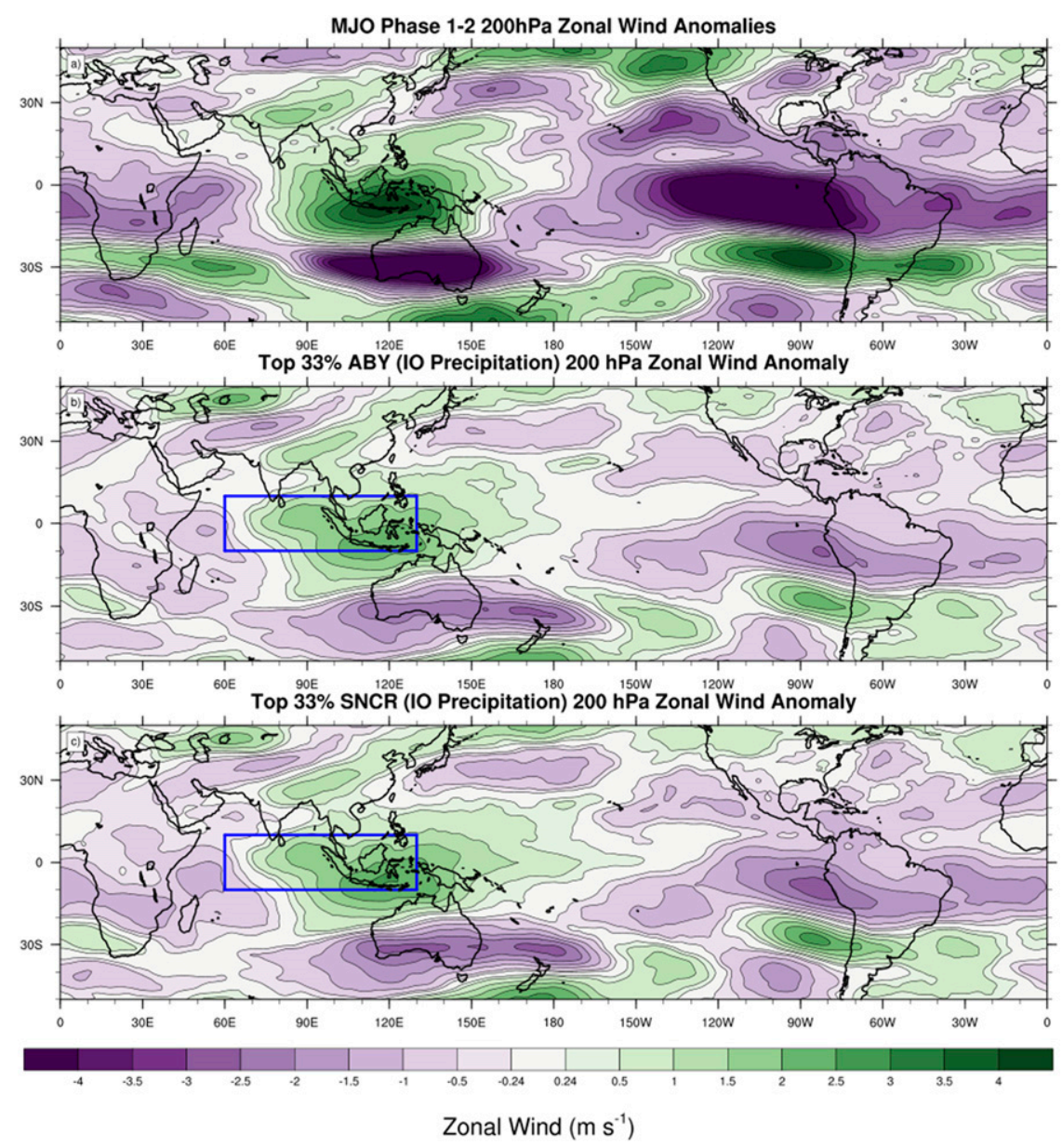

FIG. B2. (a) Normalized 200-hPa zonal wind anomalies in association with MJO phases 1 and 2. The $200-\mathrm{hPa}$ zonal wind anomalies in association with area average precipitation over a portion of the Indian Ocean and Maritime Continent $\left(10^{\circ} \mathrm{S}-10^{\circ} \mathrm{N}, 60^{\circ}-130^{\circ} \mathrm{E}\right.$ shown by the blue boxes) (b) using ABY and (c) using SNCR.

subseasonal environment associated with TCs and the environment associated with the MJO suggests that the SNCR and ABY methods function as indicators of subseasonal variability. However, the GP anomalies are generally negative over the WPAC for MJO phases 6 and 7 and for the SNCR and ABY analysis, implying that unfavorable environmental conditions are associated with higher TC activity. Thus, it appears that GP is not useful in assessing TC activity on subseasonal time scales, a conclusion reached in previous studies (Wang and Moon 2017).

\section{APPENDIX D}

\section{Null Results of SNCR and ABY}

PI and vorticity in any region of the Atlantic are found not to correlate strongly with subseasonal Atlantic TC activity. PI is dependent on SSTs that vary on seasonal time scales, and hence changes in PI likely occur too slowly to be resolved by the SNCR or ABY methods (Klotzbach and Oliver 2015a). While the correlation

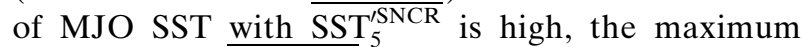
magnitude of $\overline{\mathrm{SST}}_{5}^{\mathrm{SNCR}}$ anomalies in the tropics are below $0.05{ }^{\mathrm{D} 1} \mathrm{SST}$ and PI anomalies over all regions of the Atlantic are similarly small supporting the notion that SST variability occurs too slowly to influence subseasonal TC activity. On the other hand, vorticity varies on shorter time scales in association with weather events. Because of this, signals from vorticity are likely smoothed out in our analyses. As was found for SST, the correlation of $\overline{\text { Vorticity }_{5}^{\text {SNCR }}}$

${ }^{\mathrm{D} 1}$ Percent confidence interval: from $-0.035^{\circ}$ to $0.095^{\circ} \mathrm{C}$; $p=0.37$. 

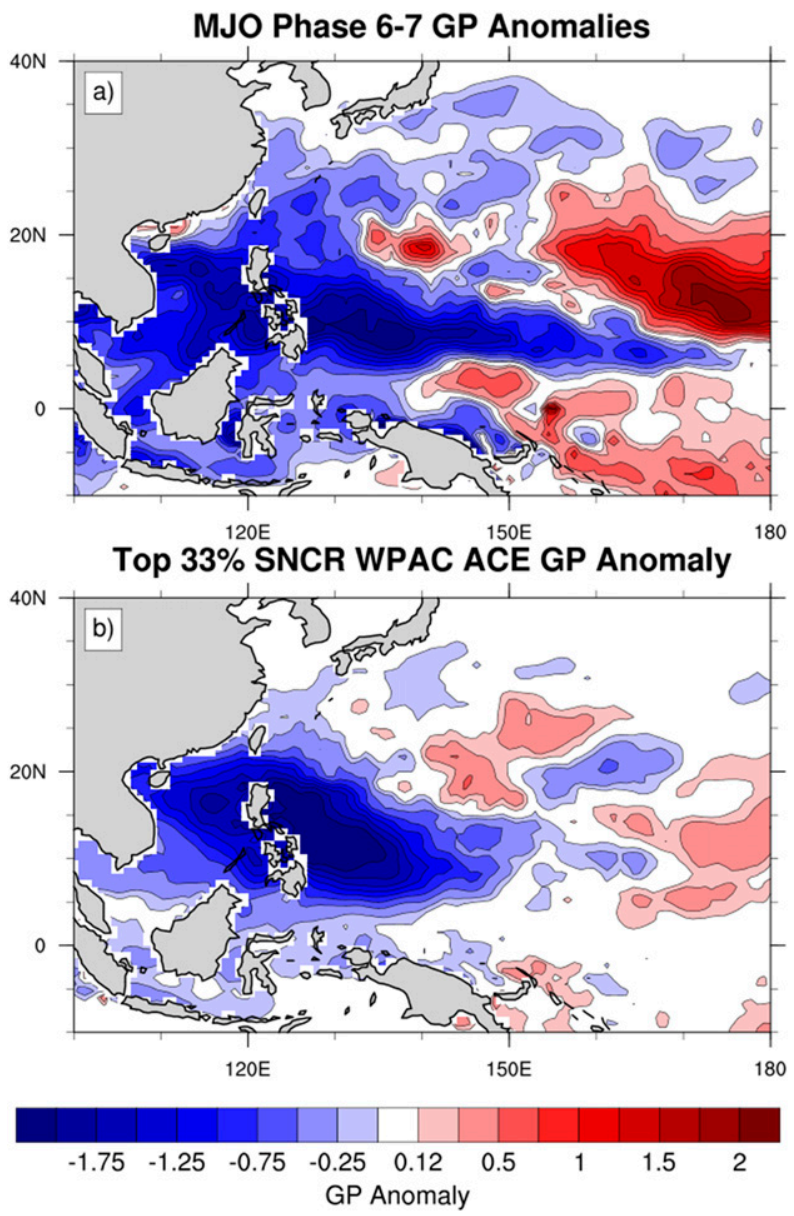

FIG. C1. Composite of $\mathrm{GP}_{5}^{\prime}$ anomalies during (a) strong MJO phases 6 and 7 (amplitude $>1$ ) and (b) the top third of SNCR ACE events in the west Pacific.

with MJO-associated vorticity is rather high, but the magnitude of Vorticity $_{5}^{\text {SNCR }}$ is low. Much of the variability in vorticity comes from TCs themselves and, as seen in Fig. D1, if TCs are not removed, subseasonal
TABLE C1. Anomaly correlation coefficients between MJO phase 6 and 7 anomalies with WPAC SNCR ACE and ABY composites of anomalies of several parameters (column 1) across different regions (row 1). ACC values greater than 0.5 are bolded.

\begin{tabular}{lccc}
\hline \hline ACC of MJO phase 6 and 7 & WPAC & Global tropics \\
\hline GP & SNCR & $\mathbf{0 . 7 2}$ & $\mathbf{0 . 7 0}$ \\
\multirow{2}{*}{ Shear } & ABY & $\mathbf{0 . 6 6}$ & $\mathbf{0 . 6 2}$ \\
& SNCR & $\mathbf{0 . 8 2}$ & $\mathbf{0 . 8 1}$ \\
RH & ABY & $\mathbf{0 . 7 5}$ & $\mathbf{0 . 7 2}$ \\
\multirow{2}{*}{ Vorticity } & SNCR & $\mathbf{0 . 5 5}$ & $\mathbf{0 . 6 2}$ \\
\multirow{2}{*}{ SST } & ABY & $\mathbf{0 . 5 4}$ & $\mathbf{0 . 5 8}$ \\
& SNCR & $\mathbf{0 . 6 3}$ & $\mathbf{0 . 5 7}$ \\
Precipitation & ABY & $\mathbf{0 . 6 2}$ & 0.48 \\
& SNCR & $\mathbf{0 . 7 7}$ & $\mathbf{0 . 7 1}$ \\
& ABY & $\mathbf{0 . 6 8}$ & 0.42 \\
& SNCR & $\mathbf{0 . 5 9}$ & $\mathbf{0 . 6 5}$ \\
\end{tabular}

anomalies of vorticity in the Atlantic basin are positive and of a high magnitude. However, vorticity does not appear to be a useful predictor, since we are looking for environmental signals of TC activity that are independent of the presence of TCs themselves. Nevertheless, Fig. D1 does help to verify our methods, to identify the ability of ABY and SNCR to capture subseasonal signals, and to understand the importance of removing TCs for subseasonal analysis. We next investigate RH. As is evident in Fig. D2b, the $\overline{\mathrm{RH}_{5}^{\prime \mathrm{ABY}}}$ signals are generally small. Weak positive $\mathrm{RH}$ anomalies exist in the Caribbean and eastern MDR, and negative RH anomalies occur in the subtropical Atlantic. The signal in $\overline{\mathrm{RH}_{5}^{\prime S N C R}}$ (not shown) is again similar to ABY. At first glance, $\mathrm{RH}_{5}^{\prime \mathrm{ABY}}$ anomalies are reminiscent of the $\mathrm{RH}$ pattern in association with the favorable MJO in the Atlantic. However, from Table 1, the ACC between RH anomalies associated with the MJO in the Atlantic and with $\overline{\mathrm{RH}_{5}^{\prime A B Y}}$ or $\overline{\mathrm{RH}_{5}^{\prime S N C R}}$ are near zero, -0.12 and -0.04 , respectively. There is a peak in

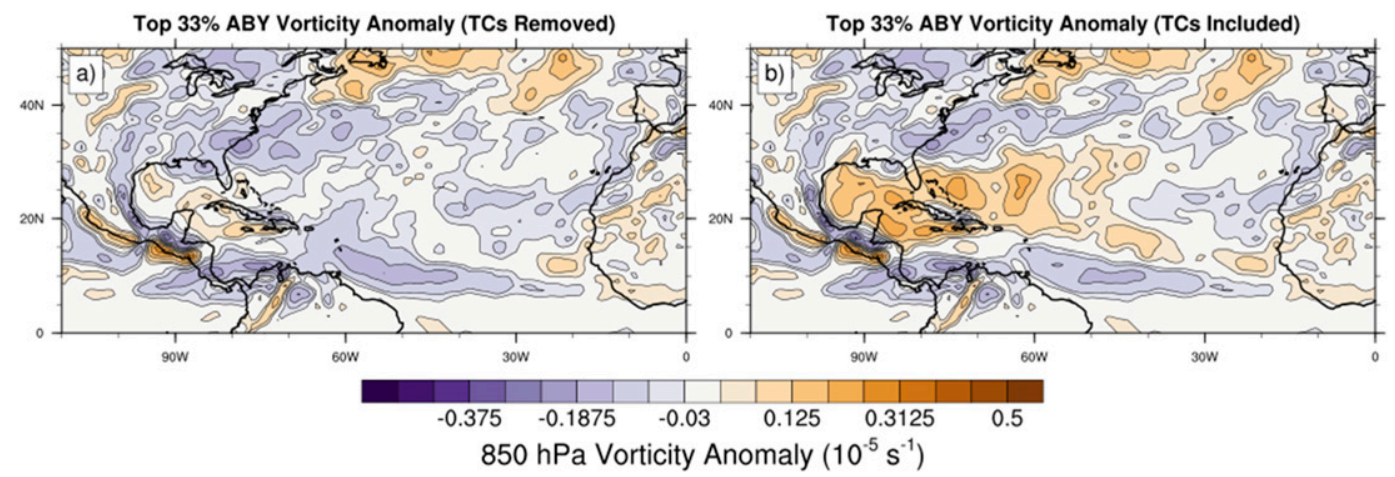

FIG. D1. Composite of vorticity anomalies during (a) $\overline{\operatorname{Vorticity}_{5}^{\prime \mathrm{ABY}}}$ with TCs removed and (b) $\overline{\text { Vorticity }_{5}^{\prime \mathrm{ABY}}}$ including TCs. 


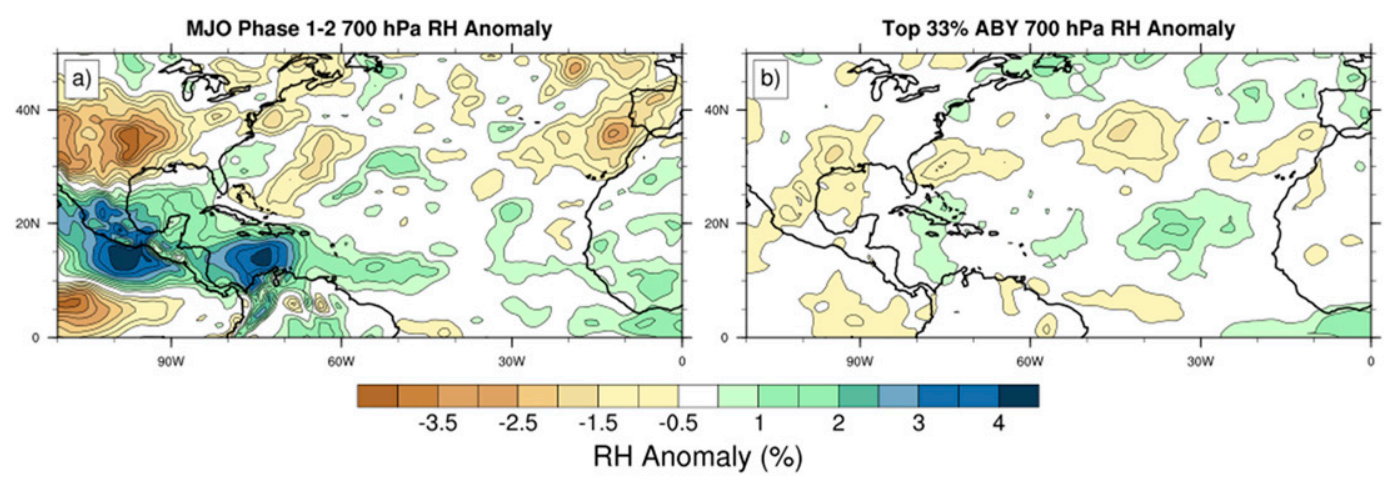

FIG. D2. Composite of RH anomalies during (a) strong MJO phases 1 and 2 and (b) the top third of ABY events in the Atlantic.

positive $\mathrm{RH}$ anomalies near Cabo Verde of $1.25 \% .{ }^{\mathrm{D} 2}$ However, given that our running means are over 5 days, this RH signal may come from incipient disturbances such as AEWs, and thus may not be a measure of the ambient environment. There are concerns with the interpretation of these $\mathrm{RH}$ values, which is discussed at the end of section 4. Additionally, the area of positive anomalies for the instantaneous RH composite is even smaller than the lagged composite in Fig. 12.

Another region with large of $\mathrm{RH}$ anomalies is the equatorial east Atlantic, which overlaps the region of positive RH anomalies in association with favorable MJO phases. This region is too far south to be associated with developing disturbances, so the connection, if it is physical, is from the background environment. However, the magnitude of anomalies differs in the SNCR and ABY analyses, and the importance of RH anomalies in this region is unclear.

${ }^{\mathrm{D} 2} n=227 ; 95 \%$ confidence interval: from $+0.3 \%$ to $2.7 \%$; $p=0.02$.

\section{REFERENCES}

Aiyyer, A., and J. Molinari, 2008: MJO and tropical cyclogenesis in the Gulf of Mexico and eastern Pacific: Case study and idealized numerical modeling. J. Atmos. Sci., 65, 2691-2704, https://doi.org/10.1175/2007JAS2348.1.

Arcodia, M. C., B. P. Kirtman, and L. S. P. Siquiera, 2020: How MJO teleconnections and ENSO interference impacts U.S. precipitation. J. Climate, 33, 4621-4640, https://doi.org/10.1175/ JCLI-D-19-0448.1.

Belanger, J. I., J. A. Curry, and P. J. Webster, 2010: Predictability of North Atlantic tropical cyclone activity on intraseasonal time scales. Mon. Wea. Rev., 138, 4362-4374, https://doi.org/10.1175/ 2010MWR3460.1.

Bell, G. D., and Coauthors, 2000: Climate assessment for 1999. Bull. Amer. Meteor. Soc., 81, S1-S50, https://doi.org/10.1175/ 1520-0477(2000)81[s1:CAF]2.0.CO;2.

Bister, M., and K. A. Emanuel, 2002: Low frequency variability of tropical cyclone potential intensity 1 . Interannual to interdecadal variability. J. Geophys. Res., 107, 4801, https://doi.org/10.1029/ 2001JD000776.

Camargo, S. J., 2013: Global and regional aspects of tropical cyclone activity in the CMIP5 models. J. Climate, 26, 9880-9902, https://doi.org/10.1175/JCLI-D-12-00549.1.

_ K. A. Emanuel, and A. H. Sobel, 2007: Use of a genesis potential index to diagnose ENSO effects on tropical cyclone genesis. J. Climate, 20, 4819-4834, https://doi.org/10.1175/JCLI4282.1.

—, M. C. Wheeler, and A. H. Sobel, 2009: Diagnosis of the MJO modulation of tropical cyclogenesis using an empirical index. J. Atmos. Sci., 66, 3061-3074, https://doi.org/10.1175/2009JAS3101.1.

Camp, J., and Coauthors, 2018: Skilful multiweek tropical cyclone prediction in ACCESS-S1 and the role of the MJO. Quart. J. Roy. Meteor. Soc., 144, 1337-1351, https://doi.org/10.1002/qj.3260.

Dalcher, A., and E. Kalnay, 1987: Error growth and predictability in operational ECMWF forecasts. Tellus, 39A, 474-491, https://doi.org/10.3402/tellusa.v39i5.11774.

Dee, D. P., and Coauthors, 2011: The ERA-Interim reanalysis: Configuration and performance of the data assimilation system. Quart. J. Roy. Meteor. Soc., 137, 553-597, https://doi.org/ 10.1002/qj.828.

DeMaria, M., and J. Kaplan, 1999: An updated Statistical Hurricane Intensity Prediction Scheme (SHIPS) for the Atlantic and eastern North Pacific basins. Wea. Forecasting, 14, 326-337, https://doi.org/10.1175/1520-0434(1999)014<0326: AUSHIP $>2.0 . \mathrm{CO} ; 2$.

Dunion, J. P., and C. S. Velden, 2004: The impact of the Saharan air layer on Atlantic tropical cyclone activity. Bull. Amer. Meteor. Soc., 85, 353-366, https://doi.org/10.1175/BAMS-85-3-353.

Elsberry, R. L., M. S. Jordan, and F. Vitart, 2010: Predictability of tropical cyclone events on intraseasonal timescales with the ECMWF monthly forecast model. Asia-Pac. J. Atmos. Sci., 46 , 135-153, https://doi.org/10.1007/s13143-010-0013-4.

Emanuel, K., and D. Nolan, 2004: Tropical cyclone activity and the global climate system. 26th Conf. on Hurricanes and Tropical Meteorology, Miami, FL, Amer. Meteor. Soc., 10A.2, https://ams.confex.com/ams/26HURR/techprogram/ paper_75463.htm.

Frank, W. M., and G. S. Young, 2007: The interannual variability of tropical cyclones. Mon. Wea. Rev., 135, 3587-3598, https:// doi.org/10.1175/MWR3435.1.

Goldenberg, S. B., and L. J. Shapiro, 1996: Physical mechanisms for the association of El Niño and West African rainfall with Atlantic major hurricane activity. J. Climate, 9, 1169-1187, https://doi.org/10.1175/1520-0442(1996)009<1169:PMFTAO > 2.0.CO;2. 
C. W. Landsea, A. M. Mestas-Nuñez, and W. M. Gray, 2001: The recent increase in Atlantic hurricane activity: Causes and implications. Science, 293, 474-479, https://doi.org/10.1126/ science. 1060040.

Gray, W. M., 1979: Hurricanes: Their formation, structure and likely role in the tropical circulation. Meteorology over the Tropical Oceans, D. B. Shaw, Ed., Royal Meteorological Society, 155-218.

_ 1984: Atlantic seasonal hurricane frequency. Part I: El Niño and $30 \mathrm{mb}$ quasi-biennial oscillation influences. Mon. Wea. Rev., 112, 1649-1668, https://doi.org/10.1175/1520-0493(1984) 112<1649:ASHFPI > 2.0.CO;2.

Hanley, D., J. Molinari, and D. Keyser, 2001: A composite study of the interactions between tropical cyclones and uppertropospheric troughs. Mon. Wea. Rev., 129, 2570-2584, https://doi.org/10.1175/1520-0493(2001)129<2570:ACSOTI> 2.0.CO;2.

Janiga, M. A., C. J. Schreck, J. A. Ridout, M. Flatau, N. P. Barton, E. J. Metzger, and C. A. Reynolds, 2018: Subseasonal forecasts of convectively coupled equatorial waves and the MJO: Activity and predictive skill. Mon. Wea. Rev., 146, 2337-2360, https://doi.org/10.1175/MWR-D-17-0261.1.

Jones, C., D. E. Waliser, K. M. Lau, and W. Stern, 2004: Global occurrences of extreme precipitation and the Madden-Julian oscillation: Observations and predictability. J. Climate, 17, 4575-4589, https://doi.org/10.1175/3238.1.

Kalnay, E., and Coauthors, 1996: The NCEP/NCAR 40-Year Reanalysis Project. Bull. Amer. Meteor. Soc., 77, 437-472, https://doi.org/10.1175/1520-0477(1996)077<0437:TNYRP > 2.0.CO;2.

Kim, H., F. Vitart, and D. E. Waliser, 2018: Prediction of the Madden-Julian Oscillation: A review. J. Climate, 31, 94259443, https://doi.org/10.1175/JCLI-D-18-0210.1.

Klotzbach, P. J., 2007: Revised prediction of seasonal Atlantic basin tropical cyclone activity from 1 August. Wea. Forecasting, 22, 937-949, https://doi.org/10.1175/WAF1045.1.

- 2010: On the Madden-Julian Oscillation-Atlantic hurricane relationship. J. Climate, 23, 282-293, https://doi.org/10.1175/ 2009JCLI2978.1.

__ 2011: El Niño-Southern Oscillation's impact on Atlantic basin hurricanes and U.S. landfalls. J. Climate, 24, 1252-1263, https://doi.org/10.1175/2010JCLI3799.1.

_ , and W. M. Gray, 2003: Forecasting September Atlantic basin tropical cyclone activity. Wea. Forecasting, 18, 1109-1128, https://doi.org/10.1175/1520-0434(2003)018<1109:FSABTC> 2.0.CO;2.

_ , and E. C. J. Oliver, 2015a: Modulation of Atlantic basin tropical cyclone activity by the Madden-Julian oscillation (MJO) from 1905 to 2011. J. Climate, 28, 204-217, https:// doi.org/10.1175/JCLI-D-14-00509.1.

_ , and - 2015b: Variations in global tropical cyclone activity and the Madden-Julian Oscillation since the midtwentieth century. Geophys. Res. Lett., 42, 4199-4207, https://doi.org/ 10.1002/2015GL063966.

Knapp, K. R., M. C. Kruk, D. H. Levinson, H. J. Diamond, and C. J. Neumann, 2010: The International Best Track Archive For Climate Stewardship (IBTrACS): Unifying tropical cyclone data. Bull. Amer. Meteor. Soc., 91, 363-376, https://doi.org/ 10.1175/2009BAMS2755.1.

Komaromi, W. A., and S. J. Majumdar, 2014: Ensemble-based error and predictability metrics associated with tropical cyclogenesis. Part I: Basinwide perspective. Mon. Wea. Rev., 142, 2879-2898, https://doi.org/10.1175/MWR-D-13-00370.1.
Kossin, J. P., and D. J. Vimont, 2007: A more general framework for understanding Atlantic hurricane variability and trends. Bull. Amer. Meteor. Soc., 88, 1767-1782, https://doi.org/ 10.1175/BAMS-88-11-1767.

Landsea, C. W., and J. L. Franklin, 2013: Atlantic hurricane database uncertainty and presentation of a new database format. Mon. Wea. Rev., 141, 3576-3592, https://doi.org/ 10.1175/MWR-D-12-00254.1.

Lee, C.-Y., S. J. Camargo, F. Vitart, A. H. Sobel, and M. K. Tippett, 2018: Subseasonal tropical cyclone genesis prediction and MJO in the S2S dataset. Wea. Forecasting, 33, 967-988, https:// doi.org/10.1175/WAF-D-17-0165.1.

Leroy, A., and M. C. Wheeler, 2008: Statistical prediction of weekly tropical cyclone activity in the Southern Hemisphere. Mon. Wea. Rev., 136, 3637-3654, https://doi.org/10.1175/ 2008MWR2426.1.

Liebmann, B., H. H. Hendon, and J. D. Glick, 1994: The relationship between tropical cyclones of the western Pacific and Indian Oceans and the Madden-Julian Oscillation. J. Meteor. Soc. Japan, 72, 401-412, https://doi.org/10.2151/ jmsj1965.72.3_401.

Lin, H., G. Brunet, and J. Derome, 2008: Forecast skill of the Madden-Julian Oscillation in two Canadian atmospheric models. Mon. Wea. Rev., 136, 4130-4149, https://doi.org/ 10.1175/2008MWR2459.1.

Maloney, E. D., and D. L. Hartmann, 2000: Modulation of hurricane activity in the Gulf of Mexico by the Madden-Julian Oscillation. Science, 287, 2002-2004, https://doi.org/10.1126/ science.287.5460.2002.

_ and J. T. Kiehl, 2002: MJO-related SST variations over the tropical eastern Pacific during Northern Hemisphere summer. J. Climate, 15, 675-689, https://doi.org/10.1175/15200442(2002)015<0675:MRSVOT>2.0.CO;2.

— , and J. Shaman, 2008: Intraseasonal variability of the West African monsoon and Atlantic ITCZ. J. Climate, 21, 28982918, https://doi.org/10.1175/2007JCLI1999.1.

McTaggart-Cowan, R., T. J. Galarneau, L. F. Bosart, R. W. Moore, and O. Martius, 2013: A global climatology of baroclinically influenced tropical cyclogenesis. Mon. Wea. Rev., 141, 19631989, https://doi.org/10.1175/MWR-D-12-00186.1.

Menkes, C. E., M. Lengaigne, P. Marchesiello, N. C. Jourdain, E. M. Vincent, J. Lefèvre, F. Chauvin, and J.-F. Royer, 2012: Comparison of tropical cyclogenesis indices on seasonal to interannual timescales. Climate Dyn., 38, 301-321, https:// doi.org/10.1007/s00382-011-1126-x.

Rasmusson, E. M., and J. M. Wallace, 1983: Meteorological aspects of the El Niño/Southern Oscillation. Science, 222, 1195-1202, https://doi.org/10.1126/science.222.4629.1195.

Robertson, A. W., F. Vitart, and S. J. Camargo, 2020: Subseasonal to seasonal prediction of weather to climate with application to tropical cyclones. J. Geophys. Res. Atmos., 125, e2018JD029375, https://doi.org/10.1029/2018JD029375.

Schreck, C. J., 2016: Convectively coupled Kelvin waves and tropical cyclogenesis in a semi-Lagrangian framework. Mon. Wea. Rev., 144, 4131-4139, https://doi.org/10.1175/MWR-D16-0237.1.

Servain, J., I. Wainer, J. P. McCreary Jr., and A. Dessier, 1999: Relationship between the equatorial and meridional modes of climatic variability in the tropical Atlantic. Geophys. Res. Lett., 26, 485-488, https://doi.org/10.1029/1999GL900014.

Tang, B. H., and J. D. Neelin, 2004: ENSO influence on Atlantic hurricanes via tropospheric warming. Geophys. Res. Lett., 31, L24204, https://doi.org/10.1029/2004GL021072. 
Tippett, M. K., S. J. Camargo, and A. H. Sobel, 2011: A Poisson regression index for tropical cyclone genesis and the role of large-scale vorticity in genesis. J. Climate, 24, 2335-2357, https://doi.org/10.1175/2010JCLI3811.1.

Ventrice, M. J., C. D. Thorncroft, and P. E. Roundy, 2011: The Madden-Julian Oscillation's influence on African easterly waves and downstream tropical cyclogenesis. Mon. Wea. Rev., 139, 2704-2722, https://doi.org/10.1175/MWR-D-10-05028.1.

Vimont, D. J., and J. P. Kossin, 2007: The Atlantic meridional mode and hurricane activity. Geophys. Res. Lett., 34, L07709, https://doi.org/10.1029/2007GL029683.

Vitart, F., 2009: Impact of the Madden-Julian Oscillation on tropical storms and risk of landfall in the ECMWF forecast system. Geophys. Res. Lett., 36, L15802, https://doi.org/10.1029/ 2009GL039089.

, A. Leroy, and M. C. Wheeler, 2010: A comparison of dynamical and statistical predictions of weekly tropical cyclone activity in the Southern Hemisphere. Mon. Wea. Rev., 138, 3671-3682, https://doi.org/10.1175/2010MWR3343.1.
_ A. W. Robertson, and D. L. Anderson, 2012: Sub-seasonal to seasonal prediction project: Bridging the gap between weather and climate. WMO Bull., 61, 23-28.

Wang, B., and J.-Y. Moon, 2017: An anomalous genesis potential index for MJO modulation of tropical cyclones. J. Climate, 30, 4021-4035, https://doi.org/10.1175/JCLI-D-16-0749.1.

Wheeler, M. C., and H. H. Hendon, 2004: An all-season real-time multivariate MJO index: Development of an index for monitoring and prediction. Mon. Wea. Rev., 132, 1917-1932, https:// doi.org/10.1175/1520-0493(2004)132<1917:AARMMI>2.0.CO;2.

White, C. J., and Coauthors, 2017: Potential applications of subseasonal-to-seasonal (S2S) predictions. Meteor. Appl., 24, 315-325, https://doi.org/10.1002/met.1654.

Zhang, C., 2005: Madden-Julian Oscillation. Rev. Geophys., 43, RG2003, https://doi.org/10.1029/2004RG000158.

Zhang, F., Y. Q. Sun, L. Magnusson, R. Buizza, S.-J. Lin, J.-H. Chen, and K. Emanuel, 2019: What is the predictability limit of midlatitude weather? J. Atmos. Sci., 76, 1077-1091, https:// doi.org/10.1175/JAS-D-18-0269.1. 